\title{
AS INCERTEZAS ASSOCIADAS ÀS CONDIÇÕES CLIMÁTICAS OBTIDAS PELO MODELO ETA CPTEC/HADCM3: AVALIAÇÃO COMPARATIVA ENTRE OS DADOS SIMULADOS E OBSERVADOS DE PRECIPITAÇÃO, EVAPOTRANSPIRAÇÃO E VAZ̃̃O NA BACIA HIDROGRÁFICA DO RIO IJUÍ, BRASIL
}

\author{
GUILHERME GARCIA DE OLIVEIRA ${ }^{1,2}$, OLAVO CORREA PEDROLLO ${ }^{1}$, NILZA MARIA DOS REIS \\ CASTRO $^{1}$
}

\author{
${ }^{1}$ Universidade Federal do Rio Grande do Sul, Instituto de Pesquisas Hidráulicas (UFRGS/IPH), \\ Porto Alegre, RS, Brasil \\ ${ }^{2}$ Centro Universitário Univates, Lajeado, RS, Brasil \\ g.g.oliveira10@gmail.com, olavopedrollo@gmail.com,nilza@iph.ufrgs.br
}

Recebido Março de 2014 - Aceito Junho de 2014

\begin{abstract}
RESUMO
Este estudo tem como objetivo avaliar as condições climáticas obtidas pelo modelo Eta CPTEC/ HadCM3, conduzido por quatro membros do modelo global HadCM3 (CNTRL, LOW, MID e HIGH), na bacia do rio Ijuí, RS. O período de controle utilizado foi de 1961 a 1975, visando a avaliação dos cenários climáticos e de vazão entre 1976 e 1990. O trabalho foi estruturado em cinco etapas: interpolação espacial dos dados climáticos; correção das séries climáticas simuladas; cálculo da evapotranspiração de referência; simulação hidrológica da vazão mensal; comparação entre as condições simuladas e as observadas de precipitação, evapotranspiração e vazão. Embora os métodos de correção utilizados para eliminar as tendências das séries climáticas simuladas tenham originado cenários bem distintos, nenhum método apresentou desempenho superior a outro em todos os critérios analisados. Tanto no caso das precipitações, quanto das vazões resultantes do processo de modelagem hidrológica, as diferenças entre os valores simulados com base no modelo Eta e os valores observados atingiram erros algumas vezes superiores a $20 \%$. Portanto, deve-se considerar que estas incertezas serão reproduzidas em cenários futuros, quanto à análise dos efeitos das mudanças climáticas na disponibilidade hídrica. Palavras-chave: Mudanças climáticas; disponibilidade hídrica; modelagem hidrológica.
\end{abstract}

\begin{abstract}
UNCERTAINTIES ASSOCIATED TO CLIMATE SCENARIOS OBTAINED BY ETA CPTEC/HADCM3 MODEL: COMPARATIVE EVALUATION BETWEEN SIMULATED AND OBSERVED DATA OF PRECIPITATION, EVAPOTRANSPIRATION AND RIVER FLOW IN IJUÍ RIVER BASIN, BRASIL.

This study aims to evaluate the climate scenarios simulated by the Eta CPTEC/HadCM3 model, conducted by four members of the HadCM3 global climate model (CNTRL, LOW, MID and HIGH), at the Ijuí River Basin, Brazil. The used control period was from 1961 to 1975, looking for the assessment of climate scenarios and river flow during the 1976 and 1990 period. The task was divided into five stages: spatial interpolation of climate data, correction of simulated climatic variables series (bias correction), calculation of reference evapotranspiration, hydrological simulation of monthly river flow, comparison between simulated and observed conditions of precipitation, evapotranspiration and river flow. Although the correction methods used to eliminate the simulated climate series biases have originated very different scenarios, neither methods presented a better performance in all examined criteria. Sometimes, the differences between the simulated values based on the Eta Model and the observed values were higher than $20 \%$, both in both rainfall and river flow resulting from the hydrologic modeling processes. Therefore, one must consider that these uncertainties will propagate to future scenarios, when analyzing the effects of climate change on water availability.
\end{abstract}

Keywords: Climate change; water availability; hydrologic modeling. 


\section{INTRODUÇÃO}

As discussões referentes à variabilidade e às mudanças climáticas se intensificaram nas últimas décadas, através de inúmeras pesquisas que comprovaram significativas alterações na composição da atmosfera e, consequentemente, nas variáveis relacionadas ao clima. Nesta temática, deve-se destacar o IPCC (Painel Intergovernamental sobre Mudanças Climáticas), estabelecido em 1988, pela Organização Meteorológica Mundial (OMM) e pelo Programa das Nações Unidas para o Meio Ambiente (PNUMA), que tem como objetivo fornecer informações científicas para melhorar o entendimento sobre as mudanças no clima global, de modo a avaliar seus impactos na sociedade e na natureza, e propor alternativas de adaptação e mitigação.

De acordo com o IPCC (2007; 2013), já é evidente o aquecimento da Terra, comprovado pelo aumento das temperaturas médias do ar e dos oceanos, pelo aumento do nível médio dos mares e pela aceleração do degelo em regiões de clima montanhoso ou polar. Através de estudos desenvolvidos em escala global, constatou-se que diversos sistemas naturais estão sendo impactados pelas mudanças do clima.

Pequenas alterações na dinâmica climática já provocam grandes impactos à sociedade humana e à biodiversidade, alterando o equilíbrio do meio ambiente (Campos, 2011). De acordo com recentes relatórios do IPCC, em virtude das mudanças de temperatura e de precipitação, deverá aumentar a frequência de eventos extremos meteorológicos, como severas enchentes e secas mais prolongadas, o que inevitavelmente afetará a disponibilidade hídrica para todas as finalidades, dentre elas, as relacionadas às atividades humanas (IPCC, 2001; 2007; 2013). Algumas pesquisas sobre a sensibilidade de culturas agrícolas às alterações no clima mostraram que poderá ocorrer um sensível efeito negativo sobre o crescimento de culturas, aumentando o risco de perdas de safras no mundo (Semenov e Porter, 1995; Mearns et al., 1996; Richter e Semenov, 2005; Zhang e Liu, 2005; Machado, 2009; Cruz et al., 2009; Campos, 2011).

As projeções de cenários climáticos são realizadas, comumente, através de Modelos Climáticos Globais (GCMs). Tratam-se de modelos numéricos capazes de descrever os principais processos físicos e dinâmicos da atmosfera, do oceano e da superfície terrestre, bem como as interações entre esses componentes e os mecanismos de retroalimentação (feedbacks), simulando a resposta do clima global às concentrações de gases de efeito estufa e de aerossóis (Giorgi e Mearns, 1991; Marengo e Valverde, 2007; Campos, 2011; Marengo et al., 2012).

No $4^{\circ}$ Relatório de Avaliação (AR4) das Mudanças Climáticas (IPCC, 2007), foram considerados 23 GCMs, elaborados em diferentes instituições de vários países, como o BCC-CM1 e FGOALS-g1.0 (China), CCSM3 e GFDL-CM (EUA), CGCM3.1 (Canadá), CSIRO-MK3.0 (Austrália), ECHO-G (Coréia do Sul/Alemanha), INM-CM3.0 (Rússia), IPSL-CM4 (França), UKMO-HadCM3 (Reino Unido) e o MIROC (Japão), entre outros. Estes modelos possuem diferentes resoluções e divergem quanto à dinâmica dos oceanos e da circulação atmosférica, não sendo possível identificar qual deles oferece o resultado mais confiável.

Para estudos regionais, não é recomendada a utilização isolada dos GCMs, em virtude da capacidade de resolução bastante limitada, geralmente superior a $250 \mathrm{~km}$ ou $2,5^{\circ}$ (Lat/ Long). A limitação da resolução espacial pode ser contornada pelo downscaling, seja pela aplicação de modelos dinâmicos regionais ou por técnicas empíricas, que consistem na transferência das informações meteorológicas para escalas de maior detalhamento (Zorita e Von Storch, 1999; Qian et al., 2003; Mello et al., 2008).

Os Modelos Climáticos Regionais (RCMs) possuem resolução entre 10 e $50 \mathrm{~km}$, o que permite a aplicação em cenários de mudanças climáticas em bacias médias e pequenas. A utilização destes modelos, em conjunto com os GCMs, possibilita o detalhamento dos processos climáticos a nível local, detectando as variações e particularidades de uma determinada região, o que melhora a compreensão de impactos em pequenas bacias (Marengo et al., 2009; 2012).

Recentemente, a partir de projetos de pesquisa e de desenvolvimento como o CREAS (Regional Climate Change Scenarios for South America), foram desenvolvidos vários experimentos com a utilização de RCMs como condições de contorno de diversos GCMs para estudar as mudanças climáticas na América do Sul, em diferentes cenários de emissões de gases e em diferentes intervalos de tempo, até o final do século XXI (Chou et al., 2012). No projeto CREAS foram utilizados três RCMs (RegCM3, HadRM3 e Eta-CCS), considerando os cenários de emissão de gases A2 e B2 do IPCC SRES (Relatório Especial Sobre Cenários de Emissões), disponível em IPCC (2000), fornecidos pelo GCM HadAM3P. A resolução horizontal foi de $50 \mathrm{~km}$, tanto para o período de controle (19611990), quanto para o período futuro (2070-2100). Estudos que utilizaram RCMs para o estudo das mudanças climáticas na América do Sul podem ser observados em Solman et al. (2008), Nuñez et al. (2008), Garreaud e Falvey (2008), Soares e Marengo (2008), da Rocha et al. (2009), Marengo et al. (2009) e Menéndez et al. (2010).

Recentemente, uma nova versão do modelo Eta, o Eta CPTEC, foi desenvolvida de forma independente pelo Instituto Nacional de Pesquisas Espaciais (INPE). O modelo Eta CPTEC inclui o aumento dos níveis de concentração de $\mathrm{CO}_{2}$ conforme o cenário de emissão e a variação diária do estado da vegetação durante o ano. Este modelo reproduz o cenário A1B do IPCC 
SRES, fornecido pelo modelo global acoplado oceano-atmosfera HadCM3, em 4 membros (versões) de perturbação do modelo global (sem perturbação - CNTRL; baixa sensibilidade - LOW; média sensibilidade - MID; alta sensibilidade - HIGH), que representam a incerteza das condições de contorno. O modelo regional foi integrado na resolução horizontal de $40 \mathrm{~km}$, para o período entre 1961 e 1990 e os cenários futuros foram gerados em três períodos de 30 anos (de 2011 a 2040, de 2041 a 2070, de 2071 a 2100) (Chou et al., 2012).

Pesquero (2009), Chou et al. (2012) e Marengo et al. (2012) utilizaram o Modelo Eta. Nos dois primeiros estudos, o modelo foi utilizado para reproduzir o clima presente sobre a América do Sul e atestar a qualidade do modelo. Foi observada uma suave tendência de subestimativa na precipitação sobre a Amazônia na estação chuvosa e na região central do Brasil, no Cerrado Brasileiro. No último estudo (Marengo et al., 2012), o modelo Eta CPTEC foi usado para estudar as mudanças climáticas nas bacias dos rios Amazonas, São Francisco e Paraná, entre 2011 e 2100.

Entretanto, nenhum dos estudos listados acima teve como enfoque a modelagem hidrológica em função do clima simulado pelos GCMs e RCMs, visando a análise da disponibilidade hídrica no passado recente (1961-1990), que constitui-se em um problema de alta complexidade, em virtude da expressiva aleatoriedade e variabilidade espacial e temporal dos fenômenos climáticos e hidrológicos. Deste modo, visando a aplicação de cenários futuros do clima em modelos hidrológicos, faz-se necessário primeiramente avaliar a qualidade das condições climáticas simuladas no passado, visando comparar não somente as variáveis climáticas observadas e simuladas, mas também as vazões resultantes do processo de modelagem hidrológica.

Com base nesta argumentação, este estudo tem como objetivo propor uma metodologia para avaliar as condições climáticas simuladas através do modelo Eta CPTEC/HadCM3, com ênfase no estudo da disponibilidade hídrica. Este estudo será aplicado à bacia hidrográfica do rio Ijuí, Rio Grande do Sul (RS), Brasil.

\section{MATERIAIS E MÉTODOS}

O conjunto de métodos adotados neste estudo compreendeu a utilização de dados pluviométricos, climáticos e hidrológicos, observados e simulados, para verificar a consistência dos cenários climáticos fornecidos pelo modelo climático regional Eta $\mathrm{CPTEC} / \mathrm{HadCM} 3$, nos quatro membros com diferentes sensibilidades climáticas: CNTRL, LOW, MID e HIGH. Como não é possível avaliar os cenários propostos para o século XXI, uma vez que não se dispõem de dados observados, o período de controle, no qual aplicam-se as correções e calibra-se o modelo hidrológico, foi definido entre 1961 a 1975, e o período de avaliação, no qual verifica-se os resultados referentes aos cenários climáticos e à disponibilidade hídrica, foi de 1976 a 1990.

\section{1 Área de estudo}

A seção relativa ao posto fluviométrico Santo Ângelo, na bacia do rio Ijuí, situa-se no noroeste do RS, Brasil. A bacia possui $5.414 \mathrm{~km}^{2}$ e está localizada entre as seguintes coordenadas geográficas: latitudes de $27,98^{\circ} \mathrm{S}$ a $28,74^{\circ} \mathrm{S}$ e longitudes de $53,21^{\circ} \mathrm{O}$ e $54,28^{\circ} \mathrm{O}$ (Figura 1). Neste posto fluviométrico, entre 1941 e 2005, a vazão média $(\bar{Q})$ foi de 138 $\mathrm{m}^{3} / \mathrm{s}$, tendo como períodos de estiagem e de cheia os meses de março $\left(=72 \mathrm{~m}^{3} / \mathrm{s}\right)$ e de outubro $\left(=211 \mathrm{~m}^{3} / \mathrm{s}\right)$, respectivamente. Como não existem significativos armazenamentos a montante do posto, principalmente se for considerado o período em análise, estes valores de vazão não foram submetidos ao processo de naturalização, sendo uma síntese das vazões apresentadas na série obtida no sistema HidroWeb.

A escolha da área de estudo se deve, primeiramente, ao fato de estar sendo realizado um monitoramento pelo Instituto de Pesquisas Hidráulicas da Universidade Federal do Rio Grande do Sul (IPH/UFRGS), desde 1989 em sub-bacias da região, com disponibilidade de um banco de dados hidrológicos superior a 20 anos (Castro et al., 1999; 2000; 2010). Em segundo lugar, a região é altamente dependente de atividades agrícolas, podendo sofrer sérios impactos socioeconômicos com as alterações climáticas. Além disso, Borges e Bordas (1988) consideraram a região representativa das características climáticas do Planalto Basáltico da Bacia Sedimentar Sul-americana, que possui mais de $1.200 .000 \mathrm{~km}^{2}$.

Considerando os dados diários climáticos do posto Cruz Alta, operado pelo INMET (Instituto Nacional de Meteorologia), os meses do inverno e primavera são os mais chuvosos. De acordo com Rossato (2011), a precipitação média anual oscila entre 1.700 e $1.800 \mathrm{~mm}$, entre 100 e 120 dias de chuva por ano, em média. A temperatura média anual oscila entre 17 e $20^{\circ} \mathrm{C}$. Os meses mais frios são junho e julho, com média em torno dos $14^{\circ} \mathrm{C}$, e os meses mais quentes são janeiro e fevereiro, com média em torno dos $24^{\circ} \mathrm{C}$.

\subsection{Materiais}

Os seguintes materiais foram utilizados neste estudo:

i) séries históricas diárias de precipitações disponibilizadas através do portal HidroWeb, da Agência Nacional de Águas (ANA), no período entre 1961 e 1990, em 77 postos pluviométricos no raio de abrangência de $100 \mathrm{~km}$ dos limites da bacia (Figura 2); 


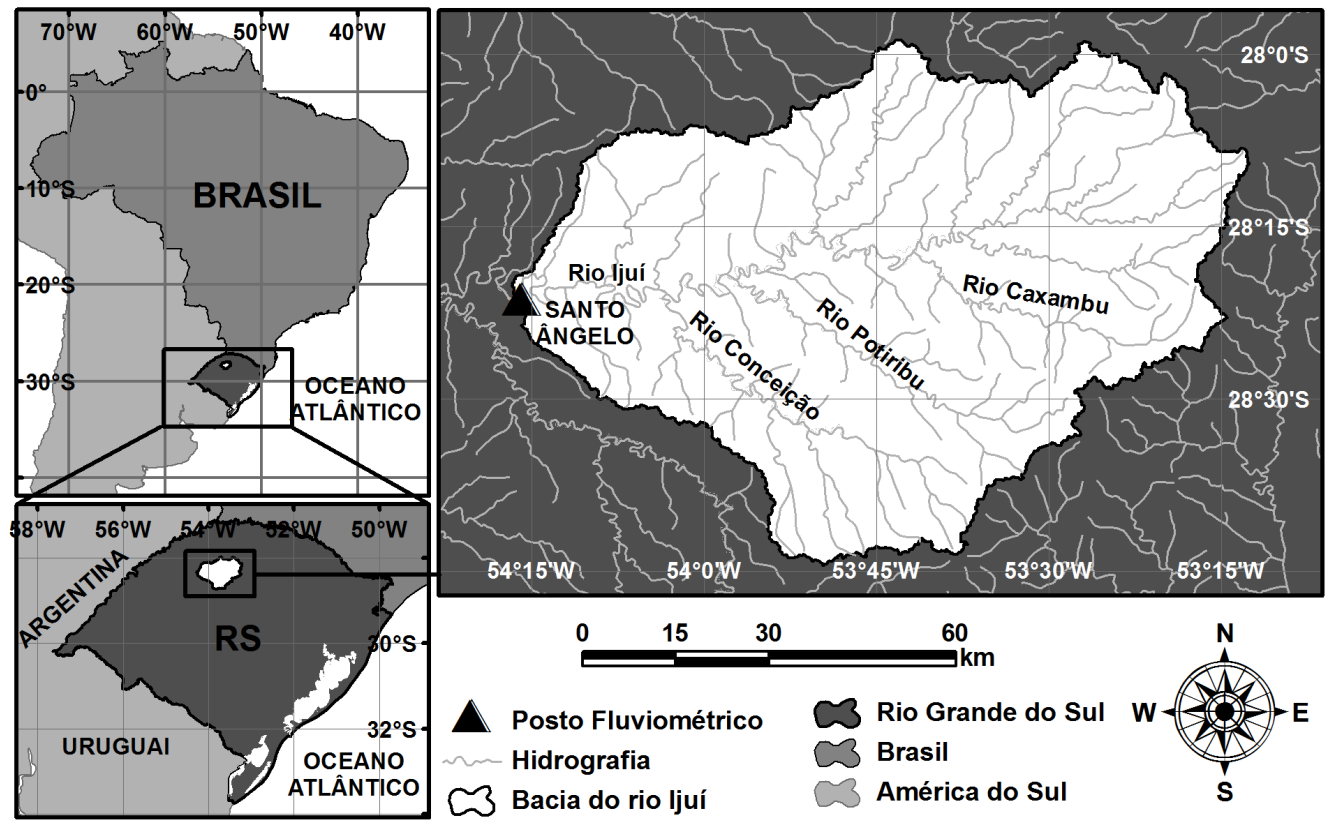

Figura 1 - Localização da bacia hidrográfica do rio Ijuí, seção a montante do posto fluviométrico Santo Ângelo $(5.414$ km²), RS, Brasil.

ii) séries históricas diárias de precipitações disponibilizadas pelo IPH (Castro et al., 2000), nos anos de 1989 e 1990, em 22 postos pluviométricos (Figura 2);

iii) séries históricas diárias de precipitação, temperatura, velocidade do vento, radiação solar, pressão atmosférica e umidade relativa do ar, disponibilizadas através do portal BDMEP (Banco de Dados Meteorológicos para Ensino e Pesquisa) do INMET, no período entre 1961 e 1990, em cinco postos meteorológicos (Figura 2);

iv) série histórica diária de vazões do posto Santo Ângelo (Cód.: 75230000 ), localizado nas coordenadas $28,36^{\circ} \mathrm{S}$ e $54,27^{\circ} \mathrm{O}$, disponibilizada no portal HidroWeb, no período entre 1961 e 1990 ;

v) dados diários simulados pelo modelo climático regional Eta CPTEC, conduzidos por quatro membros do modelo climático global HadCM3, com diferentes níveis de sensibilidade (CNTRL, LOW, MID e HIGH), no período entre 1961 e 1990. As variáveis simuladas foram: precipitação, temperatura, velocidade dos ventos, umidade relativa do ar, pressão atmosférica e radiação solar.

\subsection{Métodos}

O trabalho foi estruturado em cinco etapas: i) interpolação espacial da temperatura, velocidade dos ventos, umidade relativa do ar, pressão atmosférica e radiação solar; ii) correção (Bias Correction) das séries simuladas de precipitação, temperatura, velocidade dos ventos, umidade relativa do ar, pressão atmosférica e radiação solar; iii) cálculo da evapotranspiração de referência pelo método de Penman-Monteith; iv) simulação hidrológica da vazão mensal, com o uso de Redes Neurais Artificiais (RNAs); v) avaliação comparativa entre as condições simuladas e as observadas de precipitação, evapotranspiração e vazão.

\subsubsection{Interpolação espacial}

A primeira etapa consistiu na interpolação espacial das cinco variáveis climáticas diárias (temperatura, velocidade dos ventos, umidade relativa do ar, pressão atmosférica e radiação solar) e da precipitação diária, no período entre 1961 e 1990. A grade de interpolação foi gerada com resolução espacial de $5 \mathrm{~km}$ (Figura 2), totalizando 264 nós na área de bacia. O procedimento de interpolação foi executado para todos os conjuntos de dados: i) séries observadas em 104 postos pluviométricos e/ou meteorológicos; ii) séries simuladas através do modelo Eta CPTEC/HadCM3 em quatro cenários de sensibilidade climática (CNTRL, LOW, MID e HIGH).

A utilização de tantos postos, em um raio de $100 \mathrm{~km}$, para iniciar o processo de interpolação consiste em uma margem de segurança, já que muitos destes postos apresentam séries pouco extensas, com muitas falhas. Deste modo, apenas em alguns dias, em que os postos mais próximos da grade de interpolação apresentam falhas, o método é capaz de selecionar dados de chuva de postos localizados um pouco mais distantes, evitando, portanto, falhas na estimativa da precipitação durante o processo de interpolação. Assim, 


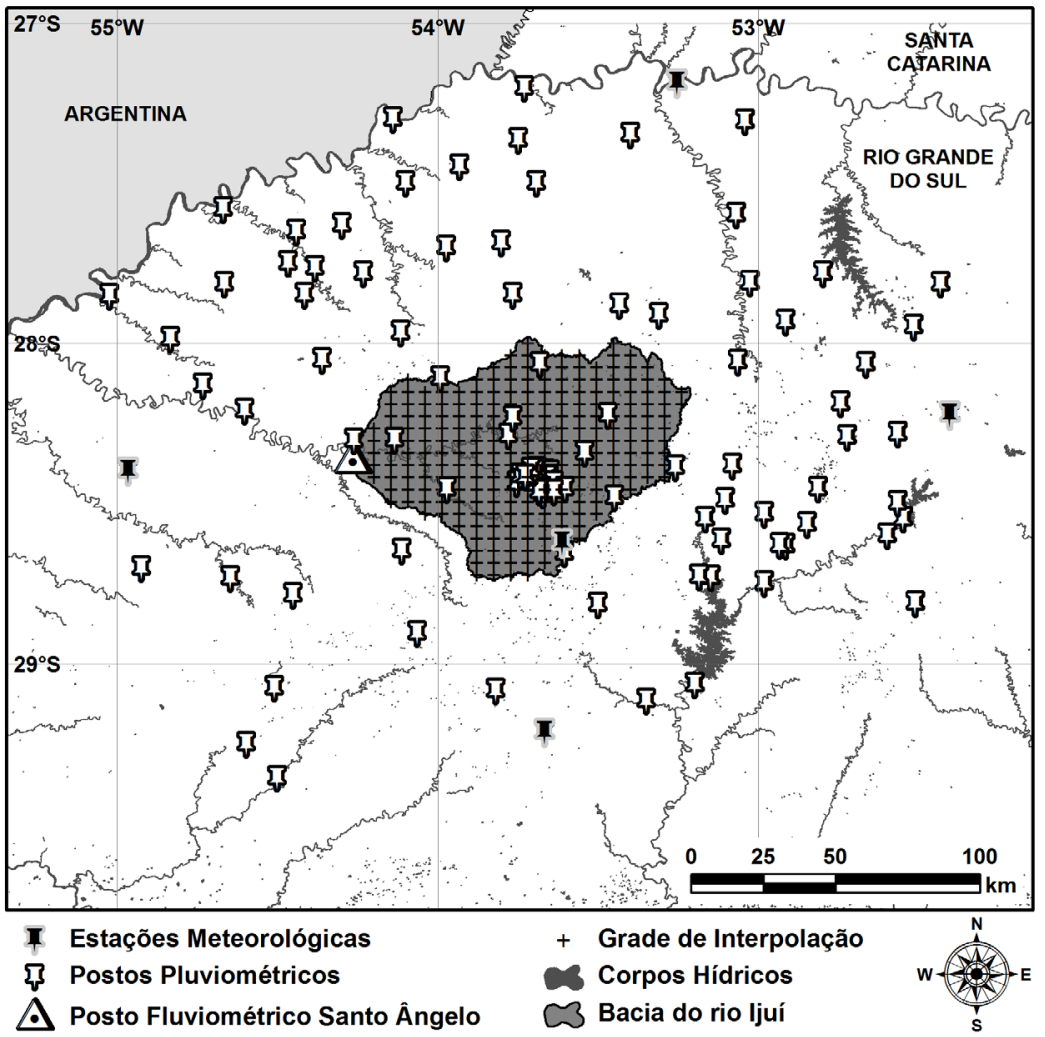

Figura 2 - Localização dos postos com dados hidrológicos e climáticos utilizados em um raio de abrangência de 100 km em relação à bacia do rio Ijuí.

pode-se afirmar que, para cada dia, em cada nó da grade de interpolação, foram utilizados apenas os postos com dados de chuva mais próximos, normalmente no interior da bacia e no entorno imediato.

O método de interpolação utilizado foi o do vizinho natural. Este método de interpolação foi o que obteve os melhores resultados no estudo apresentado por Silva (2011), com séries semelhantes às que foram utilizadas no presente trabalho, também na bacia do rio Ijuí. No estudo citado foram testados também os seguintes métodos: vizinho mais próximo, triangulação linear e o inverso ponderado das distâncias.

O método do vizinho natural (Sibson, 1981) baseia-se no conceito de área de influência dos pontos amostrais, determinada pelos polígonos de Voronoi. Estes polígonos são obtidos a partir da triangulação de Delaunay. Para cada ponto da grade de interpolação, é calculado o peso de cada ponto amostral em virtude da área de influência. O valor diário de cada variável na bacia foi obtido pela média dos valores interpolados em todos os nós da grade regular.

Por fim, nesta etapa, foi calculado o valor médio diário das cinco variáveis climáticas e da precipitação na bacia hidrográfica do rio Ijuí, considerando os dados observados e os dados simulados pelo modelo Eta.

\subsubsection{Correção dos dados simulados pelo Modelo Eta}

As saídas dos modelos climáticos não devem ser utilizadas de forma direta para a estimativa de disponibilidade hídrica no futuro (Graham, 2000). Assim, é importante testar alguns métodos de correção destes dados, com a finalidade de remover as diferenças entre o que foi simulado e o observado. Em Lenderink et al. (2007), por exemplo, foi constatada uma grande diferença entre a vazão do rio modelada a partir das condições climáticas observadas na série histórica e a vazão modelada a partir da simulação das condições climáticas no mesmo período através de modelos climáticos.

Recentemente, foram desenvolvidas e comparadas diversas técnicas de correção das variáveis climáticas resultantes dos GCMs e RCMs (Theme $\beta 1$ et al., 2012). O uso de perturbações (Delta Change Approach) nas variáveis climáticas e na precipitação é uma estratégia comumente utilizada para simular os impactos das mudanças climáticas, obtidos via modelos climáticos globais ou regionais, sobre os recursos hídricos (Graham, 2000, 2004; Bergström et al., 2001; Lenderink et al., 2007). A técnica consiste em utilizar apenas a mudança sazonal prevista, entre o cenário atual e o futuro, obtidos pelo modelo climático. Essa mudança é representada pela diferença entre as condições climáticas atuais e as previstas 
para o futuro, ambas as condições obtidas pelo modelo climático. A mudança prevista é incorporada à série histórica de precipitações e temperatura para gerar as séries no futuro. Assim, elimina-se o erro associado à modelagem climática das condições atuais, limitando-se às incertezas associadas à previsão de mudanças climáticas para o futuro. São exemplos da aplicação desta metodologia os estudos de Kaczmarek et al. (1996), Arnell (1998), Lettenmaier et al. (1999), Graham (2000), Bergström et al. (2001).

Entretanto, conforme mencionado pelos próprios autores (Graham, 2000; Bergström et al., 2001), e reforçado por Lenderink et al. (2007), a aplicação das mudanças previstas na temperatura ou na precipitação diretamente sobre a série observada implica em simplificações consideráveis, que podem comprometer a análise das projeções no futuro. Nessa abordagem, por exemplo, não são consideradas as prováveis alterações no número de dias chuvosos, na dispersão (variância) das chuvas ou nos valores extremos de temperatura, uma vez que a própria série observada no passado consiste na base da previsão para o futuro, e somente as variações médias sazonais são contabilizadas. Desse modo, assume-se o risco de considerar que as mesmas anomalias registradas no passado serão observadas no futuro, com pequenas alterações na magnitude mensal das variáveis climáticas, de acordo com o mês ou período do ano.

Assim, Lenderink et al. (2007) discutem e analisam de que forma a saída de um modelo climático regional deve ser corrigida para a obtenção de vazões mais realistas para o clima atual e, consequentemente, para o clima futuro. De acordo com o autor, o desenvolvimento de modelos climáticos regionais permite, através de algumas correções na saída, a sua utilização direta (Direct Approach) de projeções de temperatura e de chuva para o futuro. Este método, ao invés de acrescentar as mudanças previstas na série observada, realiza um procedimento diferente: i) detecta as diferenças entre as condições climáticas atuais, isto é, entre as condições observadas através de estações meteorológicas e as condições simuladas pelo modelo climático regional; ii) aplica essas diferenças na série prevista para o futuro.

Outros métodos mais sofisticados tem sido testados e comparados, com aplicações em intervalos de tempo diário ou mensal, como pode ser observado em Wood et al. (2004), Maurer e Hidalgo (2008), Ines e Hansen (2006), Boé et al. (2007), Leander e Buishand (2007), Piani et al. (2010) e Bárdossy e Pegram (2011). Em estudo recente, Theme $\beta 1$ et al. (2011) comparou alguns métodos de correção e concluiu que a técnica Quantile-Based Mapping (Panofsky e Brier, 1968) é a mais eficiente para remover os erros nos dados de precipitação. Este método é aplicado com pequenas adaptações nos estudos listados acima. Basicamente, o método se baseia nas diferenças entre as curvas de probabilidade acumulada (simulada e observada) das precipitações diárias ou mensais.

\subsubsection{Correção da precipitação simulada pelo Modelo Eta}

Inicialmente, foi realizado o cálculo da precipitação acumulada mensal para a série observada e para os quatro cenários simulados pelo modelo Eta. Em seguida, as séries foram divididas em dois períodos: i) período de controle (1961-1975); ii) período de avaliação (1976-1990).

Foram testados quatro métodos de correção sobre as séries de precipitação mensal simulada pelo modelo Eta, no período entre 1976-1990, resultando em 16 cenários corrigidos de precipitação mensal, sendo quatro cenários corrigidos para cada membro original (CNTRL, LOW, MID e HIGH).

A correção da precipitação fornecida pelo modelo Eta no período de avaliação (1976-1990) foi realizada considerando as diferenças observadas no período de controle (1961-1975), entre os dados observados e simulados, seguindo métodos distintos:

Método de Correção ${ }^{\circ}$ 1: chamado de Delta Change Approach, foi utilizado, por exemplo, por Graham (2000) e Bergström et al. (2001). A precipitação corrigida no período de avaliação (1976-1990), no mês $k$, no ano $j$, sendo que $j$ varia de 1 a 15 (ambos os períodos possuem 15 anos), é igual à precipitação observada no período de controle (1961-1975), no mês $k$, no ano $j$, multiplicada por um fator de correção. $\mathrm{O}$ fator de correção neste método corresponde à razão entre as médias da precipitação simulada no período de avaliação e no período de controle, no mês $k$ (Equação 1). Assim, neste método, os mesmos padrões de precipitação observados no passado são transferidos para o futuro, promovendo apenas alterações na magnitude das precipitações de acordo com a tendência estabelecida pelo modelo Eta.

$$
\begin{aligned}
& \operatorname{Pcor}(76-90)_{k / j}=\operatorname{Pobs}(61-75)_{k / j} \\
& *\left[\overline{\operatorname{Psim}(76-90)_{k}} / \overline{\operatorname{Psim}(61-75)_{k}}\right]
\end{aligned}
$$

Onde, Pcor $(76-90)_{\mathrm{k} / \mathrm{j}}$ é a precipitação corrigida no período de avaliação (1976-1990), no mês k e no ano j; Pobs $(61-75)_{\mathrm{k} / \mathrm{j}}$ é a precipitação observada no período de controle (1961-1975), no mês k e no ano j; $\overline{P \operatorname{sim}(76-90)_{\mathrm{k}}}$ é a média da precipitação simulada no período de avaliação para o mês k; $\overline{P \operatorname{sim}(61-75)_{\mathrm{k}}}$ é a média da precipitação simulada no período de controle para o mês $\mathrm{k}$.

Método de Correção $\mathrm{n}^{\circ} 2$ : método de aplicação direta (Direct Approach) utilizado por Lenderink et al. (2007). A precipitação corrigida no período de avaliação (1976-1990), no mês $k$, no ano $j$, é igual à precipitação simulada no mesmo período, mês e ano, multiplicada por um fator de correção. $\mathrm{O}$ fator de correção neste método corresponde à razão entre a média da precipitação observada no período de controle (1961- 
1975), no mês $k$, e a média da precipitação simulada no mesmo período e mês (Equação 2). Assim, neste método, o cenário futuro obtido diretamente da aplicação do modelo climático Eta é mantido, promovendo apenas alterações na magnitude das precipitações de acordo com as diferenças verificadas no passado entre o modelo Eta e a precipitação observada.

$$
\begin{aligned}
& P \operatorname{cor}(76-90)_{k / j}=P \operatorname{sim}(76-90)_{k / j} \\
& *\left[\overline{\operatorname{Pobs}(61-75)_{k}} / \overline{\operatorname{Pstm}(61-75)_{k}}\right]
\end{aligned}
$$

Onde, $P \operatorname{sim}(76-90)_{\mathrm{k} / \mathrm{j}}$ é a precipitação simulada no período de avaliação, no mês k e no ano j; $\overline{P o b s(61-75)_{\mathrm{k}}}$ é a média da precipitação observada no período de controle para o mês k; $\overline{P \operatorname{sim}(61-75)_{\mathrm{k}}}$ é a média da precipitação simulada no período de controle para o mês $\mathrm{k}$.

Método de Correção n ${ }^{\circ}$ : método Quantile-Based, semelhante ao aplicado em Bárdossy e Pegram (2011), baseado nas diferenças entre as curvas de probabilidade acumulada das precipitações diárias. Porém, neste caso, o método foi adaptado para as precipitações mensais, com ajuste de uma distribuição estatística para cada mês, considerando somente a precipitação média na bacia.

Nesta etapa, ajustou-se algumas distribuições estatísticas (Gamma, Log-Normal, Weibull, entre outras) aos valores de precipitação acumulada, considerando apenas o período de controle, para a série observada e a série simulada. Após a realização do teste de aderência de Kolmogorov-Smirnov, constatou-se que a distribuição de probabilidades de Weibull foi a que apresentou o melhor ajuste, na maioria dos meses do ano, em relação aos dados observados.

Em seguida, através da função ajustada à série simulada no período de controle, descobre-se a probabilidade associada a cada precipitação simulada no período de avaliação. Por fim, através da função inversa da distribuição ajustada aos dados observados no período de controle, obtém-se um novo valor de precipitação corrigido, que está associado à probabilidade obtida no passo anterior. Este procedimento foi repetido para cada mês.

A Figura 3 ilustra o procedimento. Neste exemplo, tem-se uma precipitação prevista para o período de avaliação (1976-1990) de $100 \mathrm{~mm}$, com probabilidade de ocorrência de 0,7 (círculo sólido preto). Em seguida, descobre-se a probabilidade associada a mesma precipitação na função ajustada aos dados simulados no período de controle (1961-1975), caracterizada pelo círculo circunscrito preto. Para esta última probabilidade, descobre-se o valor de precipitação correspondente na função ajustada aos dados observados no mesmo período (1961-1975). Por fim, adota-se este valor de precipitação corrigido para a série do "futuro", período de avaliação, como ilustrado pelo círculo sólido cinza.

Método de Correção $\mathrm{n}^{\circ}$ 4: método semelhante ao $\mathrm{n}^{\circ} 3$, porém com ajuste de uma distribuição estatística para as precipitações mensais a cada trimestre: Janeiro-FevereiroMarço, JFM ( $1^{\circ}$ trimestre); Abril-Maio-Junho, AMJ $\left(2^{\circ}\right.$ trimestre); Julho-Agosto-Setembro, JAS ( $3^{\circ}$ trimestre); OutubroNovembro-Dezembro, OND ( $4^{\circ}$ trimestre).

\subsubsection{Correção dos dados climáticos simulados pelo Modelo Eta}

Neste item, foi testado apenas um método de correção sobre as séries de climáticas diárias simuladas pelo modelo Eta, no período entre 1976-1990, resultando em quatro cenários corrigidos, sendo um cenário corrigido para cada membro original (CNTRL, LOW, MID e HIGH). Assim como nas precipitações, a correção dos valores das variáveis climáticas, fornecidas pelo modelo Eta no período de avaliação (1976-1990), foi realizada considerando as diferenças observadas no período de controle (1961-1975), entre os dados observados e simulados.

O método de correção, neste caso, se baseia na proposta de Lenderink et al. (2007), técnica de aplicação direta (Direct Approach): o valor da variável climática corrigida $z$, sendo $z$ uma das cinco variáveis climáticas utilizadas neste estudo, no período de avaliação (1976-1990), no dia $i$, mês $k$, no ano $j$, é igual ao valor da mesma variável, simulada no período de avaliação (1976-1990), no dia/mês/ano correspondente, somada à diferença entre a média da variável climática observada no período de controle (1961-1975), no mês $k$, e a média da mesma variável simulada no mesmo período e mês (Equação 3). Assim, neste método, o cenário futuro obtido diretamente da aplicação do modelo climático Eta é mantido, promovendo apenas alterações na magnitude das variáveis climáticas de acordo com as diferenças verificadas no passado entre o modelo Eta e observado.

$$
\begin{aligned}
& C_{z} \operatorname{cor}(76-90)_{i / k / j}=C_{z} \operatorname{sim}(76-90)_{i / k / j} \\
& +\left[\overline{C_{z} \text { obs }(61-75)_{k}}-\overline{C_{z} \operatorname{sim}(61-75)_{k}}\right]
\end{aligned}
$$

Onde, $C_{z} \operatorname{cor}(76-90)_{\mathrm{i} / \mathrm{k} / \mathrm{j}}$ é o valor da variável climática $\mathrm{z}$ corrigida para o período de avaliação, no dia i, no mês k, no ano j; $C_{z} \operatorname{sim}(76-90)_{\mathrm{i} / \mathrm{k} / \mathrm{j}}$ é o valor da mesma variável climática simulada no mesmo período, dia, mês e ano; $\overline{C_{z} o b s(61-75)_{\mathrm{k}}}$ é a média observada da variável climática $\mathrm{z}$, no período de controle, no mês k; $\overline{C_{z} \operatorname{sim}(61-75)_{\mathrm{k}}}$ é a média simulada da variável climática z, no período de controle, no mês k.

\subsubsection{Cálculo da evapotranspiração de referência}

$\mathrm{Na}$ terceira etapa, foi realizado o cálculo da evapotranspiração de referência (diária) para os quatro cenários climáticos simulados e corrigidos, e para a série observada, no período entre 1976 e 1990. O cálculo da evapotranspiração de referência foi realizada pelo método de Penman-Monteith 


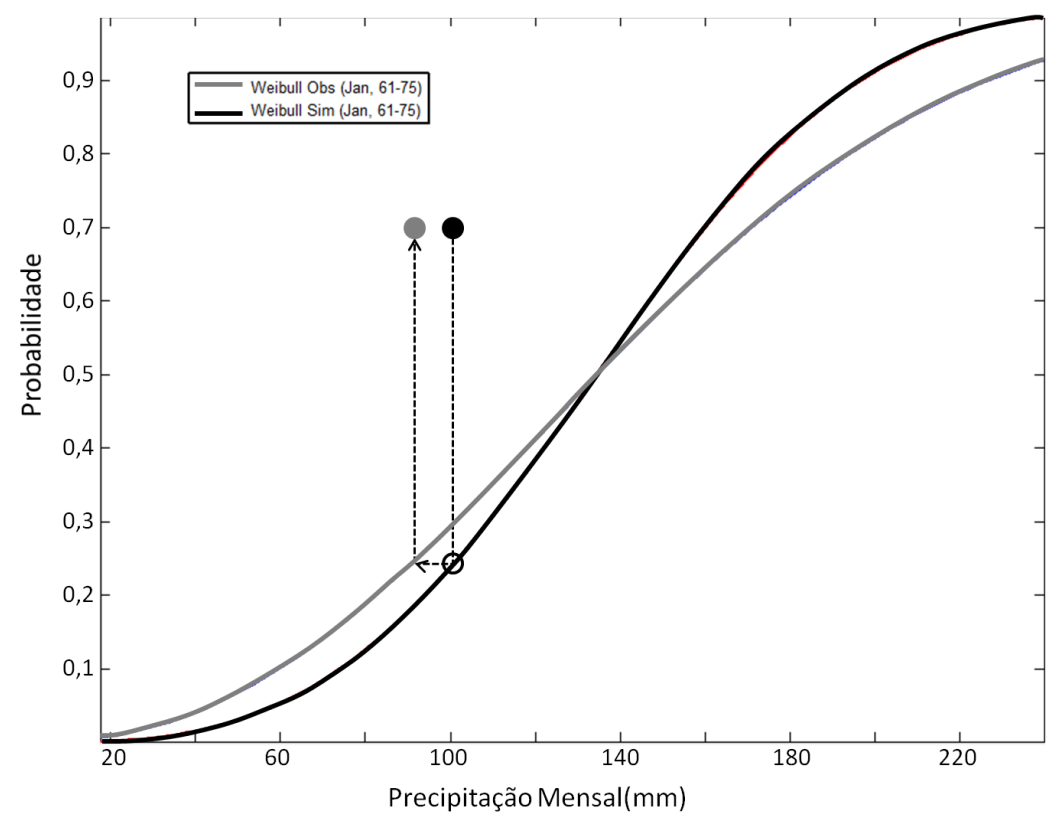

Figura 3 - Procedimento de correção das precipitações mensais com base nas curvas de probabilidade acumulada. O círculo sólido preto indica uma precipitação prevista para o "futuro" (período de avaliação) pelo modelo Eta. O círculo circunscrito preto caracteriza a probabilidade de não excedência associada a mesma precipitação na função ajustada aos dados simulados no período de controle (1961-1975). O valor de precipitação, correspondente à probabilidade indicada pelo círculo preto projetada na função ajustada aos dados observados no período de controle, é adotado no período de avaliação (círculo sólido cinza).

(Penman, 1948; Monteith, 1965), que tem sido considerado por diversos autores como o método mais confiável (Sediyama, 1996; Allen et al., 1998), sendo adotado como o método padrão pela Organização das Nações Unidas para a Agricultura e Alimentação (FAO). Este método está parametrizado para uma área totalmente coberta com grama de $12 \mathrm{~cm}$ de altura, considerando a resistência aerodinâmica da superfície de 70 $\mathrm{s} . \mathrm{m}^{-1}$ e albedo de 0,23 , em solo sem déficit hídrico.

Após o cálculo da evapotranspiração diária, estes valores foram convertidos para o intervalo de tempo mensal, compatibilizando com as séries de precipitação acumulada mensal para a modelagem hidrológica.

\subsubsection{Simulação hidrológica com uso de redes neurais artificiais}

A criação das RNAs está ligada à publicação de McCulloch e Pitts (1943) com inspiração puramente biológica. A rede possuía apenas capacidade de representar, embora de forma semelhante aos neurônios biológicos, funções lógicas simples. Somente com o algoritmo retropropagativo, desenvolvido por Rumelhart et al. (1986), é que as RNAs passaram a ser difundidas e receber investimentos em pesquisa de forma contínua e crescente.

O algoritmo retropropagativo é uma generalização, aplicada às redes multicamadas, da Regra Delta, criada por
Widrow e Hoff (1960). A atualização dos pesos de um neurônio depende apenas dos erros, das entradas e da derivada do próprio neurônio. Os erros da camada interna de neurônios são calculados a partir dos erros e das propriedades (pesos e derivadas) da camada de neurônios de saída.

Recentemente, diversas pesquisas obtiveram excelentes resultados com a aplicação de RNAs na área de recursos hídricos e hidrologia, principalmente no desenvolvimento de modelos para simulação, previsão e classificação (Bowden et al., 2005; Jain e Kumar, 2007; Leahy et al., 2008; Oliveira et al., 2014a).

A metodologia adotada neste estudo compreendeu o uso de um modelo hidrológico baseado em RNAs, composto por transformações das variáveis meteorológicas e pluviométricas. O modelo é detalhado e avaliado na pesquisa de Oliveira et al. (2014b). O treinamento da rede foi realizado através do algoritmo retropropagativo com validação cruzada. A simplificação da RNA, com redução de variáveis de entrada e de neurônios na camada interna, foi realizada através de um algoritmo que verifica o desempenho do modelo após a imposição de pequenas perturbações nos dados de entrada da RNA. A avaliação dos modelos testados foi efetuada através de análises visuais comparativas dos hidrogramas e das curvas de permanência, de indicadores quantitativos de desempenho e de uma análise de sensibilidade para compreender e interpretar o funcionamento da RNA. 
O modelo hidrológico mensal com RNAs selecionado para a área deste estudo, conforme é descrito em Oliveira et al. (2014b), apresenta apenas três variáveis de entrada, totalizando 16 pesos sinápticos. As entradas são: i) saldo médio de água (diferença entre a precipitação e a evapotranspiração) nos tempos $t$ e $t-1$; ii) valores transformados da precipitação pela aplicação de um filtro de decaimento exponencial (Equação 4); iii) valores transformados do saldo de água pela aplicação de um filtro de decaimento exponencial (Equação 5).

$$
f P_{t}=(1-\alpha) \cdot f P_{t-1}+\alpha \cdot P_{t}
$$

Onde: $\mathrm{fP}_{\mathrm{t}}$ e $\mathrm{fP}_{\mathrm{t}-1}$ são os valores transformados pela aplicação do filtro de decaimento exponencial à precipitação, nos tempos te t-1, respectivamente; $\mathrm{P}_{\mathrm{t}}$ é a precipitação no tempo t; $\alpha$ é um coeficiente que foi calibrado por tentativas, de modo a aumentar a correlação linear (r) entre a variável filtrada e a vazão observada. Na série utilizada neste estudo obteve-se um valor igual a 0,52 para este coeficiente.

$$
f S_{t}=(1-\beta) \cdot f S_{t-1}+\beta \cdot S_{t}
$$

Onde: $\mathrm{fS}_{\mathrm{t}}$ e $\mathrm{fS}_{\mathrm{t}-1}$ são os valores transformados pela aplicação do filtro de decaimento exponencial ao saldo de água, nos tempos t e $\mathrm{t}-1$, respectivamente; $\mathrm{S}_{\mathrm{t}}$ é o saldo de água no tempo t; $\beta$ é um coeficiente que foi calibrado, de modo semelhante à Equação 4. Na série utilizada neste estudo obteve-se um valor igual a 0,41 para este coeficiente.

$\mathrm{Na}$ fase de avaliação do modelo hidrológico, detalhado no estudo de Oliveira et al. (2014b), foi obtido coeficiente de Nash-Sutcliffe (NS) igual a 0,904, com RMSE (Root Mean Square Error) de $37,1 \mathrm{~m}^{3} / \mathrm{s}$. O desempenho deste modelo foi mais consistente do que o obtido com o modelo hidrológico conceitual SMAP (NS: 0,672). Através de uma análise de sensibilidade, foi observado que a RNA escolhida relacionou corretamente as variáveis de entrada com a saída da rede, respeitando os princípios físicos envolvidos no sistema hidrológico. Além disto, verificou-se que o modelo apresentou razoável capacidade de extrapolação, tendo em vista que foram testados valores de entrada que excediam os domínios utilizados no treinamento da RNA, sem comprometer o resultado esperado para as vazões.

\subsubsection{Avaliação dos cenários - análise comparativa}

Quanto à precipitação e à evapotranspiração, foram avaliados apenas três indicadores para cada: Precipitação e evapotranspiração média anual; ii) Precipitação e evapotranspiração média mensal; iii) Curva anual de probabilidade de excedência das precipitações mensais e das evapotranspirações mensais.

Em relação à vazão, foram avaliados os seguintes itens: i) Vazão média de longo período (QMLP); ii) Vazão média mensal; iii) Desvio padrão das vazões mensais; iv) Curva anual de permanência das vazões médias mensais; v) Curvas trimestrais de permanência das vazões médias mensais; vi) Vazões baixas, com permanência superior a $90 \%(\mathrm{Q}>90)$; vii) Vazões altas, com permanência inferior a $10 \%(\mathrm{Q}<10)$.

\section{RESULTADOS E DISCUSSÕES}

\subsection{Análise comparativa da precipitação simulada (1976-1990)}

Neste item, foram avaliados os 16 cenários de precipitação, no período entre 1976 e 1990, simuladas pelo modelo Eta, nos quatro membros (CNTRL, LOW, MID e HIGH), considerando os quatro métodos de correção (M1, M2, M3 e M4). Os cenários foram comparados à série observada de precipitações na bacia do rio Ijuí, sendo analisada a precipitação média anual, a precipitação média mensal e a curva anual de probabilidade de excedência das precipitações mensais.

A precipitação média anual observada no período entre 1976 e 1990 foi de 1.838,3 mm. Em todos os 16 cenários a precipitação média anual foi subestimada (média de 1.638,8 $\mathrm{mm}$, ou seja, $200 \mathrm{~mm}$ a menos que o observado). De modo geral, os cenários com o método de correção $\mathrm{n}^{\circ} 3$ (Quantile-Based, em nível mensal) foram os que apresentaram os resultados mais consistentes, com erro médio de $-184,3 \mathrm{~mm}$ por ano. Ao comparar os quatro membros do modelo Eta, os cenários referentes ao Eta MID apresentaram os melhores resultados, com erro médio de $-134,5 \mathrm{~mm}$ por ano. Considerando todos os cenários, os melhores resultados foram verificados utilizando o modelo Eta MID, com correções n ${ }^{\circ} 1$ (Delta Change Approach) e $\mathrm{n}^{\circ} 2$ (Direct Approach), com subestimativa média de 115,5 $\mathrm{mm}$ ao ano.

A precipitação média mensal, no período entre 1976 e 1990, apresentou resultados mais consistentes ao utilizar o método de correção n ${ }^{\circ}$ (Quantile-Based, em nível trimestral), com erro percentual médio de $16,9 \%$ considerando os quatro membros do modelo Eta (CNTRL, LOW, MID, HIGH). Utilizando os métodos de correção $\mathrm{n}^{\circ} 1$ e $\mathrm{n}^{\circ} 2$, os quais oferecem resultados iguais quanto à média mensal, o erro médio foi de $24,5 \%$, enquanto que ao utilizar o método de correção $n^{\circ} 3$ obteve-se o maior erro percentual médio, de $24,9 \%$ (Figura 4).

Ao comparar os quatro membros, pode-se perceber uma pequena vantagem no desempenho do Eta MID, com erro percentual médio de $20,8 \%$, considerando os quatro métodos de correção. O erro médio na estimativa da precipitação mensal na simulação com o Eta HIGH foi de 22,3\%. Os piores desempenhos foram observados com o Eta CNTRL e o Eta LOW, com erros percentuais de $23,1 \%$ e $24,6 \%$, respectivamente. 
Considerando todos os 16 cenários de precipitação no período entre 1976 e 1990, os erros percentuais foram inferiores no primeiro trimestre do ano (janeiro, fevereiro e março), com erro médio de $10,4 \%$ na estimativa das médias mensais. O mês de março apresentou o menor erro médio (6,5\%). Entre os meses de abril e julho tem-se o período do ano em que o modelo Eta apresenta os piores índices de desempenho, com erro médio de 33,3\%. No mês de junho, o erro médio na estimativa da precipitação foi de $35,9 \%$ considerando todos os 16 cenários. Os meses de abril, maio, julho, setembro, outubro e novembro apresentaram, de modo geral, uma significativa tendência de subestimativa nas precipitações médias mensais. Por outro lado, no mês de julho verificou-se uma tendência de superestimativa nas precipitações.

O cenário de precipitação proveniente da simulação com o membro Eta MID, método de correção $n^{\circ} 4$ (MID4), foi o que apresentou o menor erro percentual médio $(16,2 \%)$ na estimativa da precipitação média mensal, considerando todos os 16 cenários. Em seis meses o erro foi inferior a 10\% (fevereiro, março, maio, julho, agosto e setembro). Neste cenário, o maior erro foi verificado no mês de novembro, com percentual de $46,1 \%$.

Quanto à probabilidade de excedência das precipitações mensais (Figura 5), no período entre 1976 e 1990, os resultados mais consistentes foram observados ao utilizar os métodos de correção $\mathrm{n}^{\circ} 1$ e $\mathrm{n}^{\circ} 2$, com erro percentual médio de $12,2 \% \mathrm{e}$ $13 \%$, respectivamente, considerando os quatro membros do modelo Eta (CNTRL, LOW, MID, HIGH).

Já ao comparar os quatro membros, foi verificada uma pequena vantagem no desempenho do Eta MID, com erro percentual médio de $10,1 \%$. O pior desempenho foi observado com o Eta CNTRL, com erro percentual de 19\%. A Figura 5 ilustra também que, embora de modo geral as curvas de probabilidade de excedência das precipitações mensais provenientes do Eta MID apresentem maior concordância com o observado, as curvas referentes ao Eta LOW possuem um ajuste mais consistente às precipitações altas, isto é, com baixa probabilidade de excedência.

Os cenários de precipitação provenientes da simulação com o membro Eta MID, métodos de correção $\mathrm{n}^{\circ} 1$ e $\mathrm{n}^{\circ} 2$ (MID1 e MID2, respectivamente), foram os que apresentaram o menor erro percentual médio na estimativa da precipitação média mensal, com valores de $8,2 \%$ e 9,2\%, respectivamente.

\subsection{Análise comparativa da evapotranspiração de referência (1976-1990)}

Neste item, foram avaliados os quatro cenários de evapotranspiração de referência, calculados pelo método de
Penman-Monteith com base nas variáveis climáticas simuladas pelo modelo Eta, nos membros CNTRL, LOW, MID e HIGH, no período entre 1976 e 1990. Os cenários foram comparados à série de evapotranspiração calculada com base no clima observado na bacia do rio Ijuí, no mesmo período. Foram analisadas a evapotranspiração média anual, a evapotranspiração média mensal e a curva anual de probabilidade de excedência da evapotranspiração mensal.

A evapotranspiração média anual calculada com base no clima observado no período entre 1976 e 1990 foi de 1334 mm. Nos quatro cenários a evapotranspiração média anual foi subestimada (média de $1.268 \mathrm{~mm}$, isto é, $66 \mathrm{~mm}$ a menos que o observado). Ainda assim, este valor é bem inferior ao observado com relação à precipitação, que de modo geral, apresentou maior subestimativa (média de $200 \mathrm{~mm}$ a menos que o observado). Este resultado condiz com o observado em outros estudos, como em Graham (2000) ou Lenderink et al. (2007), em que fica evidente a dificuldade de se modelar a dinâmica das precipitações, que apresentam ocorrência e magnitudes mais aleatórias.

Dentre os quatro membros do modelo Eta, o cenário referente ao Eta CNTRL apresentou o melhor resultado quanto à evapotranspiração anual, com erro médio de $-24 \mathrm{~mm}$. Os outros três cenários (Eta LOW, MID e HIGH) obtiveram valores semelhantes, com erro de aproximadamente $80 \mathrm{~mm}$.

Também em relação à evapotranspiração média mensal, o melhor desempenho foi obtido com o uso do Eta CNTRL, com erro percentual médio de 3,9\% (Figura 6). Porém, diferentemente da precipitação, os outros cenários também apresentaram índices satisfatórios de desempenho, com erro médio variando entre 5,8\% (Eta LOW) e 7,1\% (Eta MID). Logo, fica claro que em relação à evapotranspiração existe maior semelhança entre os membros do modelo Eta e suas variáveis climáticas.

De modo geral, considerando todos os quatro cenários de evapotranspiração, no período entre 1976 e 1990 , os erros percentuais foram inferiores nos meses mais quentes do ano, mais especificamente entre novembro e fevereiro, com erro médio de apenas $3,2 \%$. Nos demais meses, o erro médio foi de $7,2 \%$, com destaque negativo para o mês de julho e outubro, com erro de $13,4 \%$ e $10,6 \%$, respectivamente (Figura 6).

Quanto à probabilidade de excedência da evapotranspiração mensal, os resultados mais consistentes também foram observados ao utilizar o membro Eta CNTRL, com erro percentual médio de 3,2\%. Este resultado pode ser observado também na Figura 7, onde se observa que as curvas de probabilidade resultantes dos outros membros também apresentam uma boa concordância com a observada, com erros variando entre 6,2\% (Eta LOW) e 6,9\% (Eta MID). 

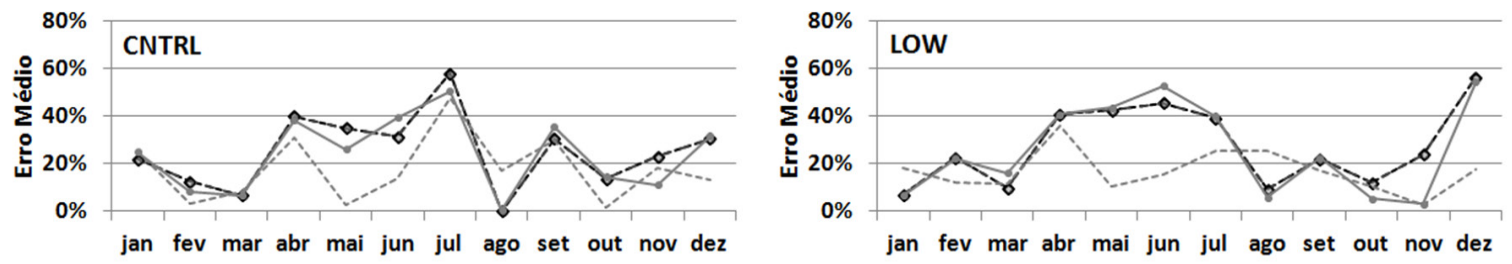

jan fev mar abr mai jun jul ago set out nov dez
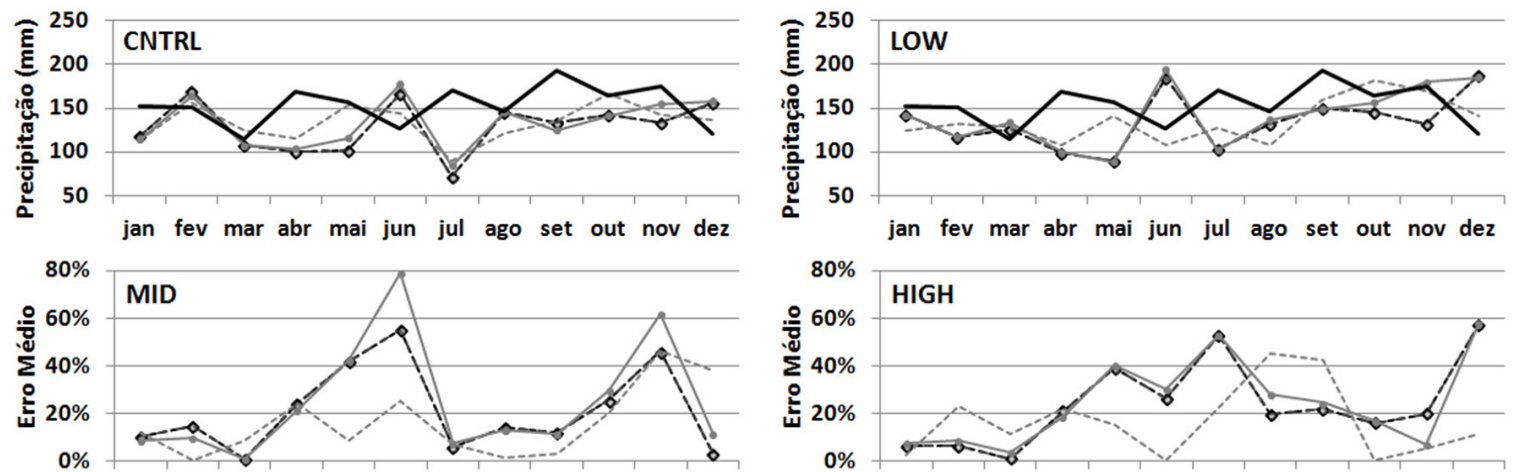

jan fev mar abr mai jun jul ago set out nov dez

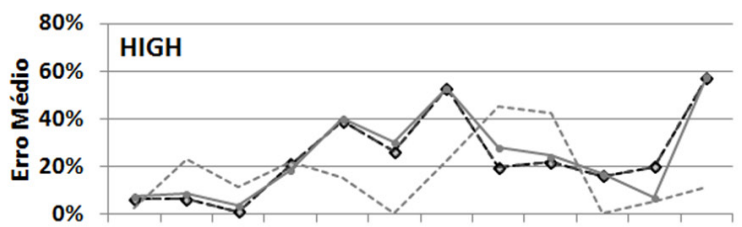

jan fev mar abr mai jun jul ago set out nov dez
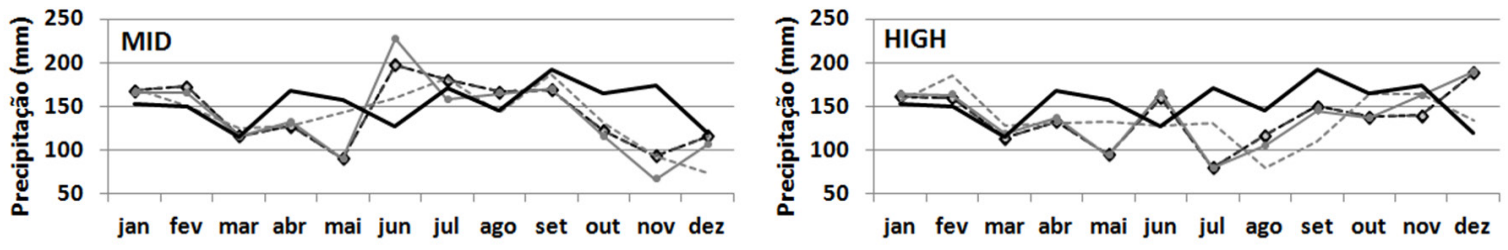

$-\leadsto$-Método $1-\theta-$ Método $2 \rightarrow-$ Método 3

---- Método 4 -OBSERVADA

Figura 4 - Erro proporcional médio e precipitação média mensal simulada e observada no período entre 1976 e 1990. Modelo Eta, membros corrigidos CNTRL, LOW, MID e HIGH.

\subsection{Análise comparativa das vazões mensais (1976- 1990)}

Neste item, foram avaliadas as 16 combinações de cenários de vazão, obtidas através da modelagem hidrológica com o uso de RNAs, tendo como base a precipitação e a evapotranspiração resultantes da simulação com o modelo Eta (membros CNTRL, LOW, MID e HIGH), no período entre 1976 e 1990. Tratam-se de quatro versões (uma para cada método de correção dos dados de precipitação) para cada membro. Os cenários foram comparados à série de vazão observada na bacia do rio Ijuí, no mesmo período.

Conforme descrito no capítulo de materiais e métodos, foram comparados e analisados os seguintes aspectos: i) vazão média de longo período (QMLP); ii) vazão média mensal; iii) desvio padrão das vazões mensais; iv) curva anual de permanência das vazões médias mensais; v) curvas trimestrais de permanência das vazões médias mensais; vi) vazões baixas, com permanência superior a $90 \%(\mathrm{Q}>90)$; vii) vazões altas, com permanência inferior a $10 \%(\mathrm{Q}<10)$.

A QMLP observada no período de avaliação, entre janeiro de 1976 e dezembro de 1990, foi de $159 \mathrm{~m}^{3} / \mathrm{s}$. De modo geral, neste aspecto, os cenários de vazão oriundos do membro
MID apresentaram os melhores resultados, com vazão média de $152 \mathrm{~m}^{3} / \mathrm{s}$, sendo o erro médio igual a $4,2 \%$. Os piores resultados foram observados nos cenários com o uso do membro CNTRL, com vazão média de $130 \mathrm{~m}^{3} / \mathrm{s}$, subestimando em $18,1 \%$ a QMLP.

Considerando os quatro métodos de correção dos dados de precipitação, os que originaram os melhores cenários de vazão, em relação à QMLP, foram os métodos n ${ }^{\circ} 3$ e n ${ }^{\circ} 4$ (Quantile-Based, em nível mensal e trimestral, respectivamente), com erro médio de $8,4 \%$ e $9,5 \%$. Nos cenários obtidos com o uso das precipitações corrigidas pelos métodos $\mathrm{n}^{\circ} 1$ e $\mathrm{n}^{\circ} 2$ (Delta Change Approach e Direct Approach) o erro foi superior, com índices em torno dos $15 \%$.

Ainda quanto à QMLP, como consequência direta da considerável subestimativa de precipitação, todos os cenários subestimaram as vazões. O cenário obtido através do membro LOW, método de correção $n^{\circ} 3$ (LOW3), aquele que apresentou o melhor desempenho, com vazão média de $156 \mathrm{~m}^{3} / \mathrm{s}$, erro de apenas $1,6 \%$. Outros cenários que merecem ser destacados são o MID1 e o MID2, com erros de 1,7\% e 4,1\%, respectivamente. Estes três cenários apresentaram o melhor desempenho neste critério, que envolve o volume médio de água escoada na bacia, principalmente, por também terem apresentado um volume de precipitação mais próximo do observado no período. 

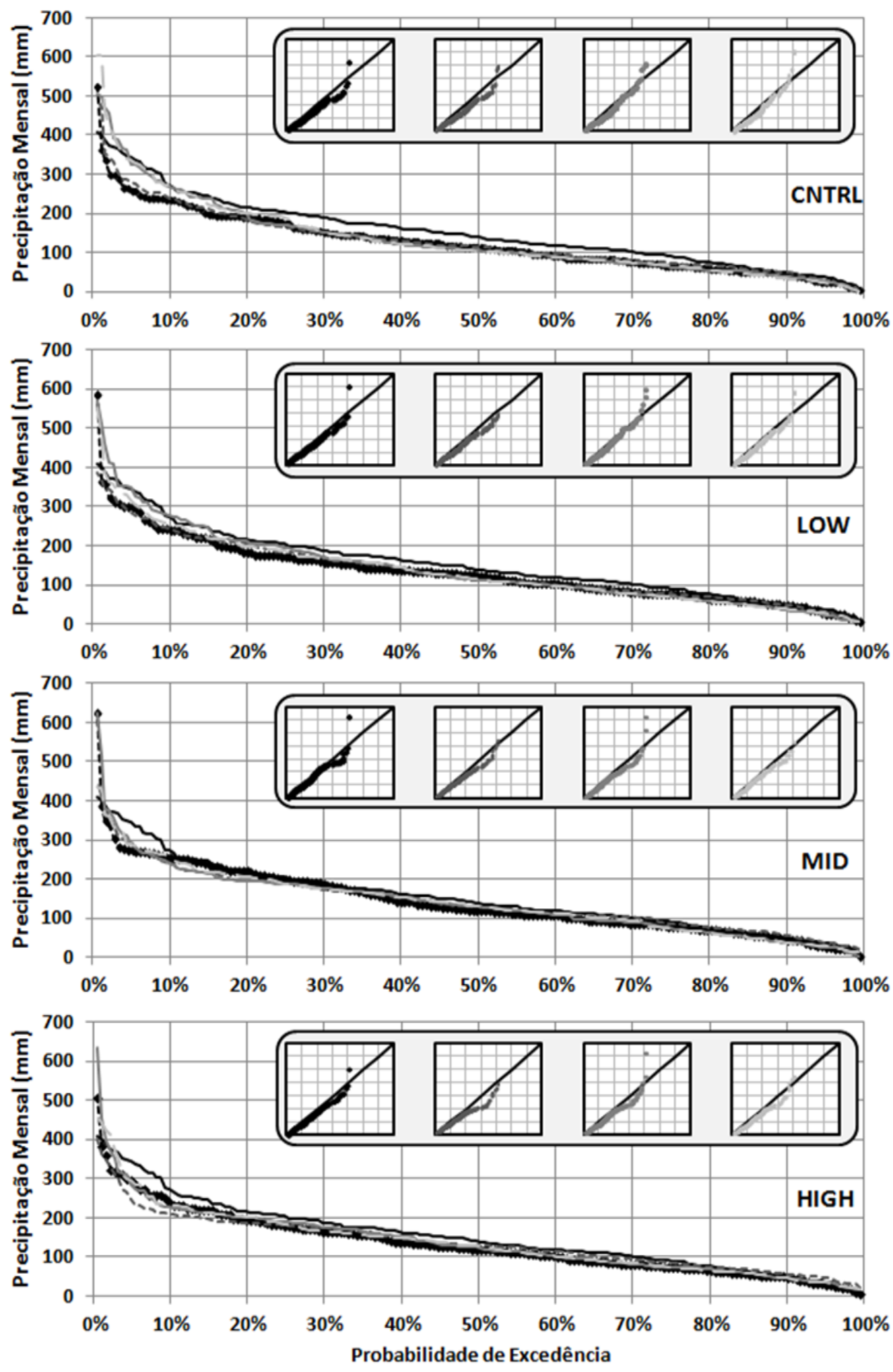

—Observado $-\rightarrow-$ Método 1 ----Método $2 \longrightarrow$ Método 3 -Método 4

Figura 5 - Probabilidade de excedência das precipitações mensais simuladas e observadas no período entre 1976 e 1990. Modelo Eta, membros corrigidos CNTRL, LOW, MID e HIGH. Os minigráficos também se referem à precipitação em função da probabilidade, sendo um gráfico cruzado: no eixo horizontal, as precipitações observadas; e no eixo vertical, as precipitações simuladas; a linha preta simboliza o ajuste ideal. 


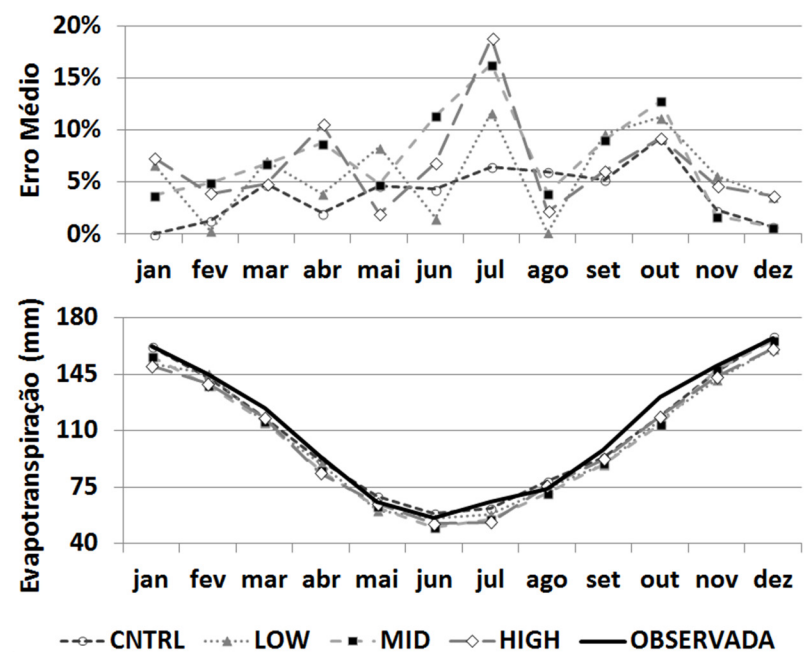

Figura 6 - Erro proporcional médio e evapotranspiração de referência média mensal simulada e observada no período entre 1976 e 1990. Eta, membros corrigidos CNTRL, LOW, MID e HIGH.

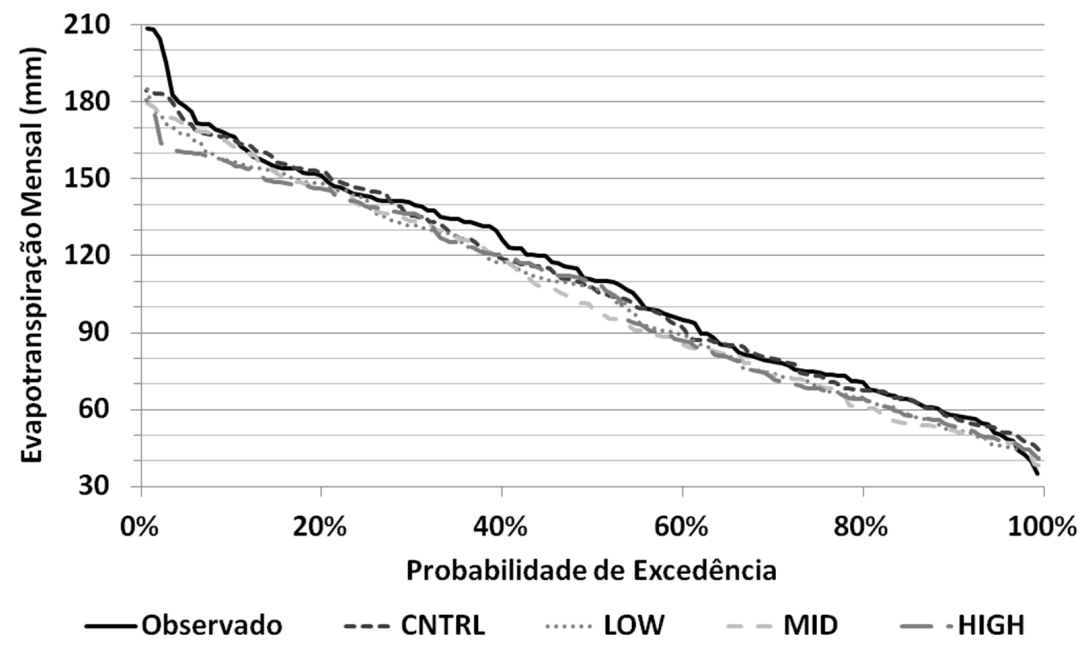

Figura 7 - Probabilidade de excedência da evapotranspiração mensal simulada e observada no período entre 1976 e 1990 . Modelo Eta, membros corrigidos CNTRL, LOW, MID e HIGH.

Com relação às vazões médias mensais, de modo geral, os cenários de vazão oriundos do membro LOW apresentaram os melhores resultados, com erro médio igual a $22,6 \%$ considerando todos os métodos de correção e meses do ano. Além disso, o padrão observado de vazões mais elevadas entre maio e novembro é melhor representado ao utilizar o membro LOW, como mostra a Figura 8. Os cenários referentes ao Eta CNTRL e Eta MID também obtiveram resultados satisfatórios, com erro médio igual a $24,1 \%$ e $26,3 \%$, respectivamente. As incertezas associadas aos cenários do Eta HIGH, no aspecto das vazões médias mensais, foram bem superiores, atingindo um erro percentual médio de $32,9 \%$.

Comparando os quatro métodos de correção dos dados de precipitação, o que originou o melhor cenário de vazão foi o método $\mathrm{n}^{\circ} 4$, com erro médio de $23,5 \%$ nos quatro membros. Os cenários de vazão obtidos com base nos dados de precipitação corrigidos pelos outros três métodos apresentaram erro médio entre $27 \%$ e $28,1 \%$.

Ao analisar os cenários individualmente, quanto à vazão média em cada mês, o melhor cenário foi o LOW4, com erro médio de $18 \%$. Em seguida, pode-se destacar os cenários CNTRL4 e MID4, com erro médio de 20,1\% e $20,8 \%$, respectivamente. Estes resultados são ilustrados pela Figura 8 , onde é possível observar que, de modo geral, os valores de vazão média mensal obtidos com o uso do método de correção Quantile-Based, em nível trimestral (método n ${ }^{\circ}$ 4), apresentam maior consistência, ajustando-se de forma mais eficiente à curva observada. A maior precisão destes cenários, quanto à estimativa da vazão média mensal, se deve principalmente ao fato destes terem apresentado valores 
de chuva média mensal mais próximos dos observados no período de análise.

A incerteza média dos cenários em relação às vazões médias mensais pode ser representada pelo erro proporcional médio de $26,5 \%$, com desvio padrão de $5,2 \%$. O pior cenário foi o $\mathrm{HIGH} 3$, com erro médio de $36,3 \%$.

Considerando os erros mensais, no mês de abril, os cenários simulados apresentaram maior consistência, com erro médio de $12 \%$. Já no mês de março, os cenários apresentaram o menor desempenho, com erro médio de $56,8 \%$ (Figura 8).

De modo geral, quanto à dispersão das vazões médias mensais no período de avaliação, os cenários de vazão oriundos do membro MID apresentaram os melhores resultados, com erro médio igual a $34,9 \%$. Comparando os quatro métodos de correção dos dados precipitação, o método $n^{\circ} 1$ é o que se destaca entre os cenários de vazão, na avaliação da dispersão dos valores mensais de vazão, com erro médio de $28,7 \%$.

Analisando individualmente os cenários de vazão, quanto ao desvio padrão das vazões mensais, o melhor cenário foi o que resultou da aplicação do método de correção $n^{\circ} 1$ aos dados de precipitação, com o membro Eta LOW (LOW1), com erro médio de $24,5 \%$. Em seguida, pode-se destacar os cenários MID4 e CNTRL1, com erro médio de 28,3\% e 29\%, respectivamente.

No mês de junho os cenários simulados apresentaram maior consistência em relação à dispersão dos valores de vazão, com erro médio de $16,9 \%$. Já no mês de fevereiro, de modo geral, os cenários apresentaram menor desempenho, com erro médio de 70,5\%, com dispersão das vazões mensais muito superior ao observado no mesmo mês durante o período entre 1976 e 1990.

Ao realizar testes de hipóteses quanto à semelhança da variância (teste $F$ ) e da média das vazões mensais (teste t), confrontando cada cenário com as vazões observadas, verificou-se que: i) no teste $\mathrm{F}$, ao nível de significância de 5\%, a hipótese nula de que as variâncias são iguais (simulado $\mathrm{x}$ observado) deve ser rejeitada em todos os cenários referentes aos membros CNTRL e HIGH, não podendo ser rejeitada nos demais cenários (Eta LOW e Eta MID); ii) já no teste t, ao nível de significância de 5\%, a hipótese nula de que médias são iguais (simulado x observado) deve ser rejeitada apenas no cenário CNTRL1.

O resultado dos testes de hipóteses indica que, em relação às vazões médias mensais, com a utilização dos cenários provenientes dos membros Eta LOW e Eta MID, independente do método de correção aplicado, a hipótese de que os valores de vazão (média e variância) simulados são semelhantes aos observados não deve ser rejeitada. Isto indica, pelo menos nos aspectos analisados, que não se pode invalidar a utilização destes cenários climáticos para a obtenção de vazões médias mensais por meio de simulação hidrológica.
Quanto às curvas de permanência das vazões mensais, considerando o período entre 1976 e 1990, a Figura 9 ilustra os resultados obtidos. De modo geral, os cenários de vazão oriundos dos membros LOW e MID novamente apresentaram os melhores resultados, com erro médio igual a $12,6 \%$ e $15,4 \%$, respectivamente. Os cenários referentes ao Eta CNTRL e Eta HIGH obtiveram resultados bem menos consistentes, com erro médio igual a $22,3 \%$ e $23,8 \%$, respectivamente.

Comparando os quatro métodos de correção dos dados precipitação, os que originaram os melhores cenários de vazão quanto à permanência foram os métodos $\mathrm{n}^{\circ} 3$ e $\mathrm{n}^{\circ} 4$, com erro médio de $17 \%$ e $16,8 \%$, respectivamente. Individualmente, o melhor cenário foi o LOW3, utilizando o membro Eta LOW, com correção das precipitações a partir do método de correção $\mathrm{n}^{\circ} 3$, com erro médio de apenas $8,7 \%$. Em seguida, pode-se destacar os cenários LOW4 e LOW2, com erro médio de $10,2 \%$ e $11 \%$, respectivamente (Figura 9). Já o pior cenário foi o HIGH2, com erro médio de $30,8 \%$ na estimativa da curva de permanência. Neste critério, a incerteza média dos cenários pode ser representada pelo erro proporcional médio de $18,5 \%$, com desvio padrão de $6,1 \%$.

De modo geral, considerando somente a parcela das vazões mais baixas (Q>90\%), os cenários de vazão oriundos dos membros CNTRL e LOW apresentaram os melhores resultados, com erro médio igual a $17,8 \%$ e $19,4 \%$, respectivamente. Estes valores foram bem superiores com o Eta MID e o Eta HIGH, com erro médio nas vazões baixas de $40,5 \%$ e $57,9 \%$, na ordem.

Comparando os quatro métodos de correção dos dados precipitação, os que originaram os melhores cenários de vazão baixas foram, novamente, os resultantes da aplicação dos métodos $\mathrm{n}^{\circ} 3$ e $\mathrm{n}^{\circ} 4$, ambos com erro médio de $25,1 \%$. Utilizando os outros métodos, o erro médio foi bem superior, na faixa entre $40 \%$ e $45 \%$. Individualmente, o melhor cenário quanto às vazões de elevada permanência (vazões baixas) foi o LOW2, com erro médio de apenas 5,3\%. Em seguida, pode-se destacar os cenários CNTRL4 e CNTRL3, com erro médio de $5,5 \%$ e $6,7 \%$, respectivamente.

Ao considerar somente a parcela das vazões mais altas, com baixo percentual de permanência $(\mathrm{Q}<10 \%)$, os cenários de vazão oriundos dos membros MID e LOW apresentaram os melhores resultados, com erro médio igual a $8,7 \%$ e $13,8 \%$, respectivamente. Comparando os quatro métodos de correção dos dados precipitação, os que originaram os melhores cenários de vazão altas também foram os métodos $n^{\circ} 3$ e $n^{\circ} 4$, com erro médio de $12,4 \%$ e $13,1 \%$, respectivamente.

Individualmente, o melhor cenário, quanto às vazões altas, foi o MID1, com erro médio de apenas 5\%. Em seguida, pode-se destacar os cenários LOW3, LOW4 e MID3, com erro médio de $5,9 \%, 7,1 \%$ e $7,4 \%$, respectivamente. Novamente, 

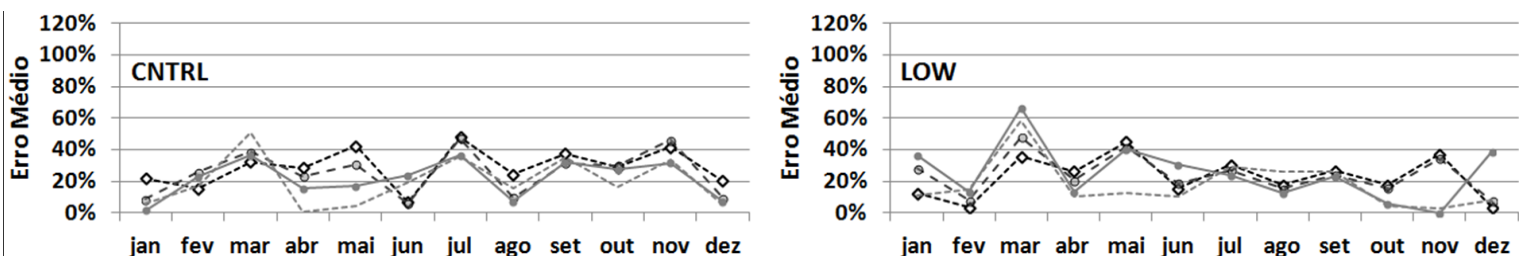

jan fev mar abr mai jun jul ago set out nov dez
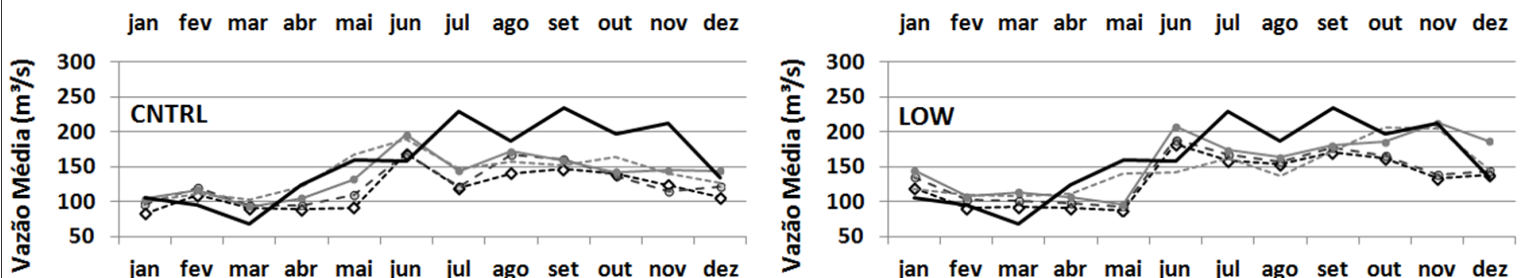

jan fev mar abr mai jun jul ago set out nov dez

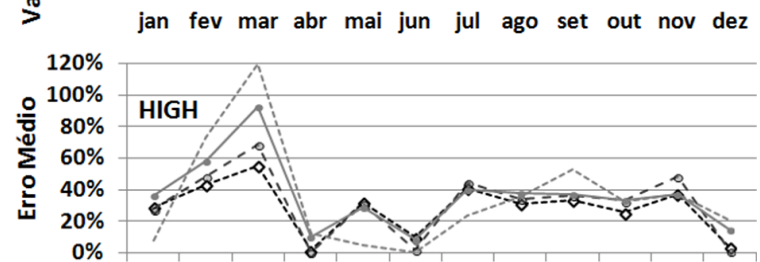

jan fev mar abr mai jun jul ago set out nov dez

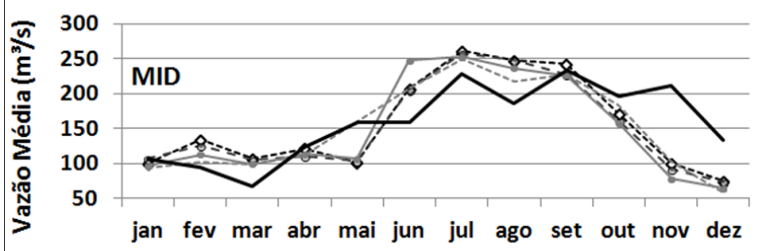

jan fev mar abr mai jun jul ago set out nov dez

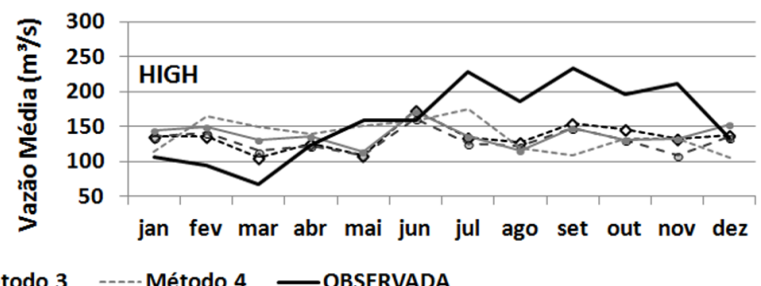

Figura 8 - Erro proporcional médio e vazão média mensal simulada e observada no período entre 1976 e 1990 . Modelo Eta, membros corrigidos CNTRL, LOW, MID e HIGH. Modelagem hidrológica com o uso de RNAs.

o pior cenário foi o HIGH2, com erro médio de $39,4 \%$ na estimativa da parcela das vazões altas da curva de permanência.

O principal aspecto físico que justifica as diferenças obtidas entre o cenário de melhor desempenho (MID1) e aquele que apresentou o pior resultado (HIGH2) é a sequência de meses com balanço positivo de água (diferença entre a precipitação e a evapotranspiração), que é uma das variáveis de entrada do modelo hidrológico. No cenário HIGH2, não foi obtido nenhum valor de saldo de água próximo ao observado, fazendo com que a maior vazão mensal, no período entre 1976 e 1990, não ultrapassasse $434 \mathrm{~m}^{3} / \mathrm{s}$. Este valor é bem inferior a maior vazão observada no mesmo período, de $676 \mathrm{~m}^{3} / \mathrm{s}$.

$\mathrm{Na}$ fase de comparação entre as curvas trimestrais de permanência das vazões mensais, simuladas e observadas, os cenários de vazão oriundos dos membros LOW e CNTRL apresentaram os melhores resultados, de modo geral, com erro médio igual a $27,3 \%$ e $28,1 \%$, respectivamente (Tabela 1 ). Os cenários referentes ao Eta MID e Eta HIGH obtiveram resultados menos consistentes, com erro médio igual a $35,4 \%$ e $40,7 \%$, respectivamente.

Individualmente, o melhor cenário foi obtido com o produto LOW2, com erro médio de $24,6 \%$ nas curvas trimestrais de permanência das vazões mensais. Em seguida, pode-se destacar os cenários CNTRL3 e CNTRL4, com erro médio de $26,9 \%$ e $27,5 \%$, respectivamente.

Conforme mostra a Tabela 1, no primeiro trimestre (JFM), os cenários referentes aos membros CNTRL, MID e LOW obtiveram os melhores desempenhos, com erro médio de $21,5 \%, 24,9 \%$ e $25,5 \%$, respectivamente. Utilizando o Eta HIGH o erro médio foi bem superior $(46,6 \%)$. Individualmente, o melhor cenário foi o CNTRL1, com erro de $12,1 \%$. Já no segundo trimestre (AMJ), os cenários referentes ao membro CNTRL obtiveram os melhores desempenhos, com erro médio de 20,3\%. Utilizando os modelos Eta LOW, MID e HIGH o erro médio foi superior, com erro médio de $28,7 \%, 49,9 \%$ e $54,8 \%$, respectivamente. Individualmente, o melhor cenário foi o CNTRL4, com erro de $13,1 \%$. No terceiro trimestre (JAS), os cenários referentes aos membros LOW e MID obtiveram os melhores desempenhos, ambos com erro médio de $27,3 \%$. Individualmente, os melhores cenários foram o MID1 e o LOW3, com erro de 23,9\% e $24,3 \%$, respectivamente. Por fim, no último trimestre (OND), os cenários referentes aos membros HIGH e LOW obtiveram os melhores desempenhos, com erro médio de $23,7 \%$ e 

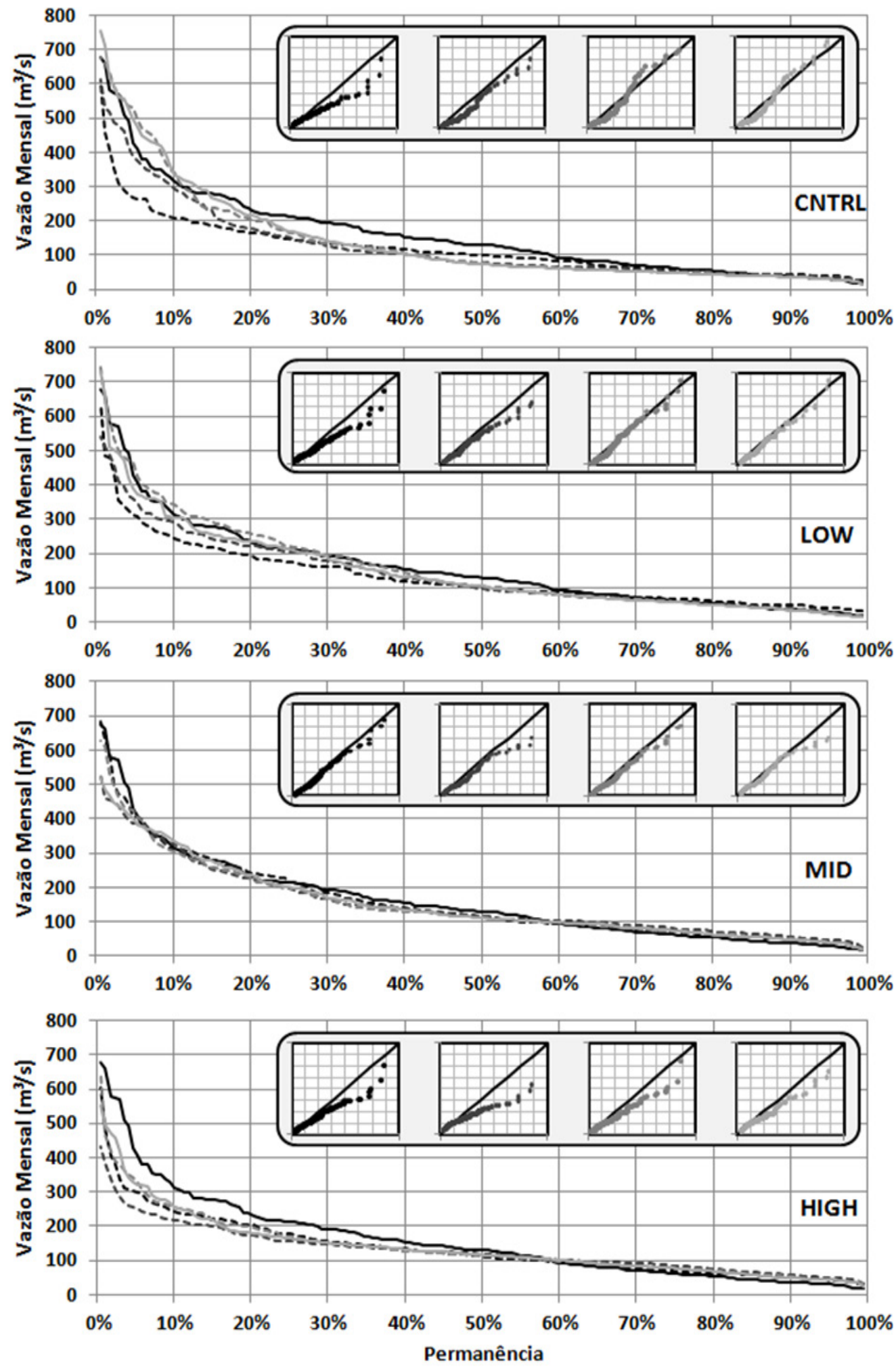

— Observado ----Método 1 ----Método 2 ----Método 3 Método 4

Figura 9 - Curvas de permanência das vazões mensais simuladas e observadas no período entre 1976 e 1990. Modelo Eta, membros corrigidos CNTRL, LOW, MID e HIGH. Os minigráficos também se referem à vazão em função da permanência, sendo um gráfico cruzado: no eixo horizontal, as vazões observadas; e no eixo vertical, as vazões simuladas; a linha preta simboliza o ajuste ideal. 
Tabela 1 - Erro médio dos cenários em relação às curvas trimestrais de permanência das vazões.

\begin{tabular}{cccccc}
\hline \multirow{2}{*}{ Cenário / Trimestre } & $\begin{array}{c}1^{\circ} \text { Trimestre } \\
\text { JFM }\end{array}$ & $\begin{array}{c}2^{\circ} \text { Trimestre } \\
\text { AMJ }\end{array}$ & $\begin{array}{c}3^{\circ} \text { Trimestre } \\
\text { JAS }\end{array}$ & $\begin{array}{c}4^{\circ} \text { Trimestre } \\
\text { OND }\end{array}$ & Média \\
\hline CNTRL1 & $12,1 \%$ & $34,6 \%$ & $38,2 \%$ & $32,6 \%$ & $29,4 \%$ \\
CNTRL2 & $24,2 \%$ & $19,3 \%$ & $38,2 \%$ & $33,1 \%$ & $28,7 \%$ \\
CNTRL3 & $23,5 \%$ & $14,4 \%$ & $35,3 \%$ & $34,6 \%$ & $26,9 \%$ \\
CNTRL4 & $26,3 \%$ & $13,1 \%$ & $37,2 \%$ & $33,6 \%$ & $27,5 \%$ \\
\hline LOW1 & $21,5 \%$ & $39,4 \%$ & $28,9 \%$ & $22,5 \%$ & $28,1 \%$ \\
LOW2 & $23,8 \%$ & $25,3 \%$ & $26,4 \%$ & $22,8 \%$ & $24,6 \%$ \\
LOW3 & $33,0 \%$ & $22,5 \%$ & $24,3 \%$ & $35,1 \%$ & $28,7 \%$ \\
LOW4 & $24,0 \%$ & $27,5 \%$ & $29,6 \%$ & $30,7 \%$ & $27,9 \%$ \\
\hline MID1 & $28,6 \%$ & $44,1 \%$ & $23,9 \%$ & $38,0 \%$ & $33,6 \%$ \\
MID2 & $30,4 \%$ & $59,3 \%$ & $31,1 \%$ & $35,5 \%$ & $39,1 \%$ \\
MID3 & $21,5 \%$ & $47,8 \%$ & $28,4 \%$ & $44,3 \%$ & $35,5 \%$ \\
MID4 & $19,1 \%$ & $48,6 \%$ & $25,9 \%$ & $39,7 \%$ & $33,3 \%$ \\
\hline HIGH1 & $44,6 \%$ & $49,7 \%$ & $36,8 \%$ & $25,4 \%$ & $39,1 \%$ \\
HIGH2 & $45,6 \%$ & $61,9 \%$ & $38,1 \%$ & $24,9 \%$ & $42,6 \%$ \\
HIGH3 & $51,7 \%$ & $54,5 \%$ & $38,5 \%$ & $20,0 \%$ & $41,2 \%$ \\
HIGH4 & $44,5 \%$ & $53,3 \%$ & $37,4 \%$ & $24,3 \%$ & $39,9 \%$ \\
\hline
\end{tabular}

$27,8 \%$, respectivamente. Individualmente, o melhor cenário foi o HIGH3, com erro de $20 \%$.

Ainda levando em consideração a análise das curvas trimestrais de permanência oriundos dos 16 cenários, porém com enfoque na parcela das vazões mais baixas $(\mathrm{Q}>90 \%)$, os cenários de vazão provenientes do membro CNTRL apresentaram os melhores resultados, com erro médio igual a $30,1 \%$. Neste aspecto, o pior desempenho foi obtido com o Eta MID, com erro médio de 72,5\%. Individualmente, os melhores cenários foram o CNTRL4, o CNTRL3 e o CNTRL2, com erro médio de $22,2 \%, 24,9 \%$ e $27,6 \%$, respectivamente.

Por outro lado, considerando somente a parcela das vazões mais altas $(\mathrm{Q}<10 \%)$, os cenários de vazão oriundos do membro MID apresentaram os melhores resultados, com erro médio igual a $22,5 \%$. Neste aspecto, o pior desempenho foi obtido com o Eta HIGH, com erro médio de 41,8\%. Individualmente, os melhores cenários foram o MID4 e MID1, com erro médio de $18,2 \%$ e $19,7 \%$, respectivamente.

Ao realizar o teste Kolmogorov-Smirnov para avaliar as curvas de permanência, quanto à semelhança entre as distribuições de frequência das vazões simuladas e a distribuição de frequência das vazões observadas, verificou-se que, ao nível de significância de 5\%, a hipótese nula de que as distribuições de frequência das vazões mensais (simuladas $\mathrm{x}$ observadas) são iguais deve ser rejeitada nos seguintes cenários: CNTRL1, CNTRL2, CNTRL3, CNTRL4, LOW1, HIGH2 e HIGH4. O resultado dos testes de hipóteses indica que, em relação à permanência das vazões, com a utilização dos cenários provenientes dos membros Eta MID, Eta LOW (métodos 2, 3 e 4) e Eta HIGH (métodos 1 e 3), a hipótese de que os valores de vazão (permanência) simulados são semelhantes aos observados não deve ser rejeitada.
Assim, não se pode invalidar a utilização de alguns cenários climáticos (corrigidos), provenientes do modelo Eta, para a obtenção de curvas de permanência de vazões mensais. Em outros termos, pode-se afirmar que os resultados indicam a viabilidade do estudo da disponibilidade hídrica no futuro com base na metodologia adotada neste estudo.

\section{CONCLUSÕES}

Neste trabalho foram avaliados cenários provenientes do modelo Eta CPTEC, em quatro membros (CNTRL, LOW, MID e HIGH) com diferentes sensibilidades envolvendo as incertezas do modelo HADCM3. Foram realizadas correções nos dados de precipitação e em cinco variáveis climáticas (temperatura, velocidade dos ventos, umidade do ar, pressão atmosférica e radiação solar) para o cálculo da evapotranspiração de referência. Para os dados de precipitação foram testados quatro procedimentos diferentes: $\mathrm{n}^{\circ} 1$ (Delta Change Approach); $\mathrm{n}^{\circ} 2$ (Direct Approach); ${ }^{\circ} 3$ (Quantile-Based, em nível mensal); n4 (Quantile-Based, em nível trimestral). Já para os outros dados climáticos foi testada apenas a técnica Direct Approach. A combinação dos membros do modelo Eta CPTEC com os métodos de correção originou 16 cenários climáticos para avaliação no período entre 1976 e 1990, tendo como referência os dados observados no período na bacia hidrográfica do rio Ijuí, RS, Brasil. A partir da modelagem hidrológica, com uso de RNAs, obteve-se também 16 cenários de vazão no período.

Considerando todos os resultados apresentados, pode-se verificar que apenas o Eta HIGH não se mostrou satisfatório na maioria dos aspectos analisados quanto à precipitação, evapotranspiração e vazão. De modo geral, os outros membros 
se intercalaram em termos de vantagens em relação ao desempenho, de acordo com o critério analisado.

Em termos de precipitação, o destaque positivo ficou com o membro Eta MID: i) subestimativa média de 134,5 mm nas precipitações anuais; ii) erro médio na estimativa das precipitações mensais de 20,8\%; iii) erro médio de 10,1\% na curva de probabilidade de excedência das precipitações mensais.

Com relação à evapotranspiração, os melhores resultados obtidos se referem ao membro CNTRL do modelo Eta: i) subestimativa média de $24 \mathrm{~mm}$ na evapotranspiração anual; ii) erro médio na estimativa da evapotranspiração mensal de $3,9 \%$; iii) erro médio de $3,2 \%$ na curva de probabilidade de excedência das evapotranspirações mensais. Porém, no caso da evapotranspiração, os outros membros também apresentaram resultados satisfatórios, com índices normalmente inferiores a $10 \%$ de erro médio.

$\mathrm{Na}$ avaliação das vazões resultantes, se destacaram os membros LOW, MID e CNTRL, com pequena vantagem ao primeiro. A versão LOW do modelo Eta apresentou os melhores resultados em relação às vazões médias mensais (erro médio de $22,6 \%$ ), às curvas anuais de permanência das vazões (erro médio de $12,6 \%$ ) e às curvas trimestrais de permanência das vazões (erro médio de 27,3\%). Além disto, pode-se observar um bom ajuste, tanto às vazões baixas (permanência superior a 90\%), quanto às vazões altas (permanência inferior a 10\%). Já a versão MID do modelo Eta apresentou os melhores resultados em relação à QMLP (erro médio de 4,2\%), à dispersão das vazões mensais (erro médio de 34,9\%) e à parcela das vazões altas das curvas anuais e trimestrais de permanência das vazões (erro médio de $8,7 \%$ e $22,5 \%$, respectivamente). Por fim, a versão CNTRL apresentou os melhores resultados em relação à parcela das vazões baixas das curvas anuais e trimestrais de permanência das vazões (erro médio de 17,8\% e 30,1\%, respectivamente).

Em análise individual, considerando todos os aspectos analisados, um dos cenários que se destacou foi o LOW2. Utilizando o membro LOW, com correção das precipitações pelo método $n^{\circ} 2$, foram obtidos os melhores resultados quanto à permanência de vazões mensais considerando a análise trimestral e também quanto às vazões baixas. Além disso, neste cenário foram obtidos bons ajustes na curva de permanência das vazões mensais considerando a análise anual.

Outro cenário que apresentou resultados consistentes foi o LOW4, principalmente no que se refere às vazões médias mensais, à curva de permanência anual das vazões mensais e às vazões altas. Já o cenário LOW3 foi o que apresentou o melhor desempenho quanto à QMLP. Este cenário também apresentou excelentes resultados em relação à curva de permanência anual das vazões mensais, com ajuste satisfatório tanto às vazões altas quanto às vazões baixas.
Além dos três cenários destacados acima, outros cenários que obtiveram resultados satisfatórios em alguns aspectos foram o MID1 (QMLP; vazões altas), o MID 4 (vazão média e desvio padrão mensal), o CNTRL3 (vazões baixas) e o CNTRL4 (vazão média mensal e vazões baixas).

Considerando os três testes de hipóteses realizados, em relação às vazões simuladas no período de avaliação, destacaram-se os cenários provenientes dos membros Eta LOW (métodos de correção 2, 3 e 4) e Eta MID (todos os métodos de correção). Com a utilização destes sete cenários climáticos, ao nível de significância de 5\%, não se pode rejeitar as hipóteses de que as médias, variâncias e curvas de permanência das vazões mensais são semelhantes às observadas.

Por fim, com base nos resultados obtidos, conclui-se que as incertezas dos cenários de precipitação do modelo Eta são muito superiores aos cenários de evapotranspiração. A imprecisão na estimativa da precipitação gera certo grau de inconsistência também nas vazões obtidas a partir do processo de modelagem hidrológica, resultando em erros algumas vezes superiores a $20 \%$ nos critérios analisados. Deve-se, portanto, considerar que estas incertezas serão reproduzidas em cenários futuros (para as próximas décadas do século XXI), tendo em vista que a metodologia a ser adotada segue os mesmos princípios da avaliação realizada neste estudo.

\section{AGRADECIMENTOS}

Agradecimento a FINEP pelo financiamento da pesquisa Chamada pública MCT/FINEP CT-HIDRO 01/2010 - Convênio 01.12.0396.00, Projeto - Rede de Pesquisa em Monitoramento e Modelagem de Processos Hidrossedimentológicos em Bacias Representativas Rurais e Urbanas do Bioma Mata Atlântica (RHIMA). Agradecimento ao CNPq pela bolsa de doutorado do primeiro autor deste estudo.

\section{REFERÊNCIAS BIBLIOGRÁFICAS}

ALLEN, R. G. et al. Crop evapotranspiration (guidelines for computing crop water requirements). Irrigation and Drainage Paper, 56, Rome: FAO, 1998. 300 p.

ARNELL, N. W. Climate change and water resources in Britain. Climatic Change, v. 39, p. 83-110, 1998.

BÁRDOSSY, A.; PEGRAM, G. Downscaling precipitation using regional climate models and circulation patterns toward hydrology. Water Resources Research, v. 47, W04505, doi:10.1029/2010WR009689, 2011.

BERGSTRÖM, S. et al. Climate change impacts on runoff in Sweden - assessments by global climate models, dynamical downscaling and hydrological modeling. Climate Research, v. 16, p. 101-112, 2001. 
BOÉ, J. et al. Statistical and dynamical downscaling of the Seine basin climate for hydro-meteorological studies. International Journal of Climatology, v. 27, p. 1643-1655, 2007.

BORGES, A. L.; BORDAS, M. P. Choix de bassins représentatifs et expérimentaux pour l'étude de l'érosion sur le plateau basaltique sudaméricain. In: Porto Alegre Symposium, 1988, Porto Alegre. Sediment Budgets. International Association Of Hydrological Sciences, Publication 174, Wallingford: IAHS, p. 161-169, 1988.

BOWDEN, G. J. et al. Input determination for neural network models in water resources applications. Part I - background and methodology. Journal of Hydrology, v. 301, p. 75-92, 2005.

CAMPOS, C. G. C. Padrões climáticos atuais e futuros de temperatura do ar na região sul do Brasil e seus impactos nos cultivos de pêssego e de nectarina em Santa Catarina. Tese (Doutorado em Meteorologia) - Instituto Nacional de Pesquisas Espaciais, São José dos Campos: INPE, 2011. $165 \mathrm{p}$.

CASTRO, N. M. R. et al. Land use change effects on runoff and erosion from plot to catchment scale on the basaltic plateau of Southern Brazil. Hydrological Processes, v. 13, n.11, p. 1621-1628, 1999.

CASTRO, N. M. R. et al. Projeto Potiribu, atualização 19891998 - dados básicos de fluviometria e pluviometria. IPH: UFRGS, Revista de Recursos Hídricos, v. 35, 2000.

CASTRO, N. M. R. et al. Relatório Final das atividades de março de 2007 a maio de 2010. Relatório de pesquisa IPH, UFRGS, Porto Alegre, Brasil, 2010.

CHOU, S. C. et al. Downscaling of South America present climate driven by 4 -member HadCM3 runs. Climate Dynamics, DOI 10.1007/s00382-011-1002-8, 2012.

CRUZ, G. et al. Levantamento de horas de frio nas diferentes regiões de Santa Catarina. Revista Agropecuária Catarinense, Florianópolis, v. 22, n. 1, p. 44-47, 2009.

DA ROCHA, R. P. et al. Precipitation diurnal cycle and summer climatology Assessment over South America: an evaluation of Regional Climate Model version 3 simulations. Journal of Geophysical Research 114:D10108. doi: 10.1029/2008JD 010212, 2009.

GARREAUD, R.; FALVEY, M. The coastal winds off western subtropical South America in future climate scenarios. International Journal of Climatology, 29:543-554. doi:10.1002/joc.1716, 2008.

GIORGI, F.; MEARNS, L. O. Approaches to the Simulation of Regional Climate Change: a Review. Reviews of Geophysics. v. 29, p. 191-216, 1991.

GRAHAM, L. P. Large-scale hydrological modeling in the Baltic basin. Division of Hydraulic Engineering, Dept of
Civil and Environmental Engineering, Royal Institute of Technology, Report TRITA-AMI PHD 1033, Stockholm, 2000.

GRAHAM, L. P. Climate change effects on river flow to the Baltic Sea. Ambio, v. 33, n. 4-5, p. 235-241, 2004.

INES, A. V. M.; HANSEN, J. W. Bias correction of daily GCM rainfall for crop simulation studies. Agricultural and Forest Meteorology, v. 138, p. 44-53, 2006.

INTERGOVERNMENTAL PANEL ON CLIMATE CHANGE - IPCC. Climate Change 2013: The physical science basis. Working Group I Contribution to the Fifth Assessment Report of the IPCC, Stockholm, September, 2013. 2216p.

INTERGOVERNMENTAL PANEL ON CLIMATE CHANGE

- IPCC. Summary for policymakers: contribution of working group I to the fourth assessment report of the Intergovernmental Panel on Climate Change. This Summary for Policymakers was formally approved at the 10th Session of Working Group I of the IPCC, Paris, February, 2007. 996p.

INTERGOVERNMENTAL PANEL ON CLIMATE CHANGE - IPCC. Climate change: the scientific basis. Cambridge University Press, Cambridge, UK, 2001. Disponível em: $<$ http://www.grida.no/publications/other/ipcc_tar/>. Acesso em 26 mar. 2012.

INTERGOVERNMENTAL PANEL ON CLIMATE CHANGE - IPCC. Emissions Scenarios. A Special Report of Working Group II of the Intergovernmental Panel on Climate Change. Cambridge University Press, Cambridge, 2000.

JAIN, A.; KUMAR, A. M. Hybrid neural network models for hydrologic time series forecasting. Applied Soft Computing, n.7, p. 585-592, 2007.

KACZMAREK, Z. et al. Climate change impacts on the water supply system in the Warta River Catchment, Poland. International Journal of Water Resources. v. 12, p. 165180, 1996.

LEAHY, P. et al. Structural optimisation and input selection of an artificial neural network for river level prediction. Journal of Hydrology, v. 355, p. 192-201, 2008.

LEANDER, R.; BUISHAND, T. A. Resampling of regional climate model output for the simulation of extreme river flows. Journal of Hydrology, v. 332, p. 487-496, 2007.

LENDERINK, G. et al. Estimates of future discharges of the river Rhine using two scenario methodologies: direct versus delta approach. Hydrology and Earth System Science, v. 11, n. 3, p. 1145-1159, 2007.

LETTENMAIER, D. P. et al. Water resources implications of global warming: A. U. S. regional perspective. Climatic Change, v. 43, p. 537-579, 1999.

MACHADO, L. N. Estimativa dos impactos gerados pelas mudanças no Estado de Santa Catarina. TCC (Graduação 
em Agronomia) - Universidade Federal de Santa Catarina, Centro de Ciências Agrárias, Florianópolis, 2009, 63p.

MARENGO, J. A.; VALVERDE, M. C. Caracterização do clima no Século XX e Cenário de Mudança de clima para o Brasil no Século XXI usando os modelos do IPCC-AR4. Revista Multiciência, v. 8, p. 5-28, 2007.

MARENGO, J. A. et al. Future change of temperature and precipitation extremes in South America as derived from the PRECIS regional climate modeling system. International Journal Climatology. Published online in Wiley InterScience. doi:10.1002/joc.1863, 2009. Disponível em: $<\mathrm{http}: / / \mathrm{www}$.interscience.wiley.com>. Acesso em 27 mar. 2012.

MARENGO, J. A. et al. Development of regional future climate change scenarios in South America using the Eta CPTEC/HadCM3 climate change projections: Climatology and regional analyses for the Amazon, São Francisco and the Parana River Basins. Climate Dynamics, v. 38, p. 1829-1848, 2012.

MAURER, E. P.; HIDALGO, H. G. Utility of daily vs. monthly large-scale climate data: an intercomparison of two statistical downscaling methods. Hydrology and Earth System Sciences, v. 12, p. 551-563, 2008.

MCCULLOCH, W.; PITTS, W. A logical calculus of the ideas immanent in nervous activity. Bulletin of Mathematival Biophisics, v. 5, p. 115-133, 1943.

MEARNS, L. O. et al. The effect of Changes in Daily and Interannual Climatic Variability on CERES-Wheat Yields: A Sensitivity Study. Climatic Change, v. 32, p. 257-292, 1996.

MELLO, E. L. et al. Efeito das mudanças climáticas na disponibilidade hídrica da bacia hidrográfica do rio Paracatu. Revista de Engenharia Agrícola, Jaboticabal, v. 28, n. 4, p. 635-644, 2008.

MENÉNDEZ, C. et al. Downscaling extreme month-long anomalies in southern South America. Climatic Change, v. 98, p. 379-403, 2010.

MONTEITH, J. L. Evaporation and environment. Symposia of the Society for Experimental Biology, XIX, p. 205234, 1965.

NUÑEZ, M. N. et al. Regional Climate change experiments over southern South America. II: climate change scenarios in the late twenty-first century. Climate Dynamics, doi:10.1007/ s00382-08-0449-8, 2008.

OLIVEIRA, G. G. et al. O desempenho das Redes Neurais Artificiais (RNAs) para simulação hidrológica mensal. Revista Brasileira de Recursos Hídricos, v. 19, n. 2, p. 251-265, 2014b.

OLIVEIRA, G. G. et al. Simplifying Artificial Neural Network models of river basin behaviour by an automated procedure for input variable selection. Artigo aceito para publicação na
Engineering Applications of Artificial Intelligence, 2014a. PANOFSKY, H. A.; BRIER, G. W. Some Applications of Statistics to Meteorology, The Pennsylvania State University, University Park, 1968. 224p.

PENMAN, H. L. Natural evaporation from open water, bare soil and grass. Proceedings of the Royal Society of London, A193, p. 120-145, 1948.

PESQUERO, J. F. Balanço de umidade na região do sistema de monção da América do Sul em cenários climáticos futuros (2071-2100) utilizando o modelo Eta: um estudo de modelagem. Tese de Doutorado. São José dos Campos. INPE, 2009. $204 \mathrm{p}$.

PIANI, C. et al. Statistical bias correction of global simulated daily precipitation and temperature for the application of hydrological models. Journal of Hydrology. doi:10.1016/j. jhydrol.2010.10.024, 2010.

QIAN, J. H. et al. Reinitialized versus Continuous Simulations for Regional Climate Downscaling. Monthly Weather Review, v. 131, p. 2857-2874, 2003.

RICHTER, G. M.; SEMENOV, M. A. Modelling impacts of climate change on wheat yields in England and Wales: assessing drought risks. Agricultural Systems, v. 84, p. 77-97, 2005.

ROSSATO, M. S. Os Climas do Rio Grande do Sul: variabilidade, tendências e tipologia. (Tese de Doutorado) Programa de Pós-graduação em Geografia, Instituto de Geociências, Universidade Federal do Rio Grande do Sul. Porto Alegre: UFRGS/PPGEA, 2011. 240p.

RUMELHART, D. E. et al. Learning representations by backpropagating errors. Nature, v. 323, p. 533-536, 1986.

SEDIYAMA, G. C. Evapotranspiração: necessidade de água para os cultivos. Brasília: ABAES, 1996. 167p.

SEMENOV, M. A.; PORTER, J. R. Climatic Variability and the Modelling of Crop Yields. Agricultural and Forest Meteorology, v. 73, p. 265-283, 1995.

SIBSON, R. A brief description of natural neighbor interpolation. In: Barnett, V. (Ed.). Interpreting Multivariate Data, Wiley, Chichester, p. 21-36, 1981.

SILVA, V. S. V. Estimativa de precipitação pontual em diferentes escalas para uso em modelo concentrado chuva-vazão. (Dissertação de Mestrado) Instituto de Pesquisas Hidráulicas da Universidade Federal do Rio Grande do Sul, Porto Alegre, Brasil, 2011.

SOARES, W. R.; MARENGO J. A. Assessments of moisture fluxes east of the Andes in South America in a global warming scenario. International Journal of Climatology. DOI: 10.1002/joc.1800, 2008.

SOLMAN, S. A. et al. Regional climate change experiments over southern South America. I: present climate. Climate Dynamics, v. 30, p. 533-552, 2008. 
THEMEßL, M. J. et al. Empirical-statistical downscaling and error correction of daily precipitation from regional climate models. International Journal of Climatology, v. 31, p. 1531-1544, 2011.

THEMEßL, M. J. et al. Empirical-statistical downscaling and error correction of regional climate models and its impact on the climate change signal, Climatic Change, v. 112, p. 449-468, 2012.

WIDROW, B.; HOFF, M. E. Adaptive switching circuits. In: 1960 IRE WESCON Convention Record, New York: IRE Part 4, p. 96-104, 1960.

WOOD, A. W. et al. Hydrologic implications of dynamical and statistical approaches to downscale climate model outputs. Climatic Change, v. 62, p. 189-216, 2004.
ZHANG, X. C.; LIU, W. Z. Simulating potential response of hydrology, soil erosion, and crop productivity to climate change in Changwu tableland region on the Loess Plateau of China. Agricultural and Forest Meteorology, v. 131, n. 3-4, p. 127-142, 2005.

ZORITA, E.; VON STORCH, H. The analog method as a simple statistical downscaling technique: comparison with more complicated methods. Journal of Climate, v. 12, p. 2474-2489, 1999. 